Revista lus et Praxis, Año 25, № 2, 2019, pp. 19 - 66

ISSN 0717 - 2877

Universidad de Talca - Facultad de Ciencias Jurídicas y Sociales

La prohibición de colocar en el mercado productos que sean peligrosos en caso

de utilización conforme a su finalidad o racionalmente previsible

Lautaro Contreras C.

Trabajo recibido el 2 de enero de 2018 y aprobado el 5 de febrero de 2019

\title{
La prohibición de colocar en el mercado productos que sean peligrosos en caso de utilización conforme a su finalidad o racionalmente previsible
}

THE PROHIBITION OF INTRODUCING INTO THE MARKET PRODUCTS THAT ARE

DANGEROUS WHEN USED NORMALLY OR IN A REASONABLY FORESEEABLE WAY

Lautaro Contreras C.

ResUMEN

La responsabilidad penal del fabricante por los delitos de homicidio y lesiones presupone, en muchos casos, la infracción de la prohibición de colocar en el mercado productos que sean peligrosos en caso de empleo conforme a su finalidad o racionalmente previsible. El propósito de este artículo consiste en analizar pormenorizadamente esta prohibición.

ABSTRACT

Producers' criminal liability for death and personal injuries presupposes, in a number of cases, the infringement of the prohibition of introducing into the market products that are dangerous when used normally or in a reasonably foreseeable way. This paper intends to provide a detailed analysis of such prohibition.

PaLABRAs CLAVE

Responsabilidad penal por el producto, Uso del producto conforme a su finalidad o racionalmente previsible, Principio de proporcionalidad

KEY WORDS

Product criminal liability, Normal or reasonably foreseeable use of the product,

Proportionality principle

El presente artículo analiza la prohibición de colocar en el mercado productos que sean peligrosos en caso de utilización conforme a su finalidad o racionalmente previsible. La infracción de esta prohibición constituirá frecuentemente el requisito básico para hacer efectiva la responsabilidad penal del fabricante, por los delitos de homicidio simple (art. $391 \mathrm{~N}^{\circ} 2$ del Código Penal chileno'), lesiones menos graves (art. 399 del CP) y lesiones leves (art. 494 No 5 del CP), a

\footnotetext{
* Profesor asociado de la Universidad de Chile, Departamento de Ciencias Penales de la Facultad de Derecho. Legum magister y doctor por la Albert-Ludwigs-Universität (Alemania). Correo electrónico: Icontreras@derecho.uchile.cl.

1 En adelante, indistintamente, "CP" o "Código Penal".
} 
título doloso o culposo, dado el caso. Para analizar los contornos específicos de la prohibición referida, es indispensable distinguir entre dos clases de bienes de consumo: productos que corresponden a "nuevos desarrollos", por una parte, y productos que ya han sido colocados en el mercado y que el fabricante quiere seguir elaborando y distribuyendo, por otra.

En la introducción del artículo comenzaremos destacando la relevancia de los delitos de homicidio simple, lesiones menos graves y lesiones leves en la responsabilidad penal por productos defectuosos, para luego detenernos en la cuestión relativa a la infracción del deber jurídico como presupuesto básico de toda responsabilidad criminal del fabricante (infra 1). A continuación, se explicará el vínculo existente entre la prohibición de colocar en el mercado productos peligrosos y los principales defectos que puede tener un bien de consumo (infra 2). Luego se analizará en detalle cómo el fabricante puede reconocer y evitar estos defectos, tratándose de productos que corresponden a "nuevos desarrollos" (infra 3). Para ello, será necesario examinar pormenorizadamente el "deber de reconocimiento de riesgos" del producto (infra 3.1), así como el "deber de reducción de riesgos" (infra 3.2). Posteriormente, se mostrará cómo se concreta la prohibición de colocar en el mercado productos que sean peligrosos en caso de utilización conforme a su finalidad o racionalmente previsible, cuando se trata de bienes de consumo que ya están en el mercado y que el fabricante quiere seguir elaborando y distribuyendo (infra 4). Finalmente, se describirán las conclusiones de la investigación (infra 5).

\section{Introducción: La relevancia de los delitos de homicidio simple, lesiones menos graves y lesiones leves para hacer efectiva la responsabilidad penal del fabricante}

La fabricación y colocación en el mercado de productos defectuosos, capaces de afectar la vida o salud de los consumidores, pueden dar origen no solo a una indemnización de perjuicios, sino también a responsabilidad criminal${ }^{2}$. Así se demostró, por ejemplo, en los famosos casos Contergan o de la colza, acontecidos en Alemania y España, respectivamente, o en el caso del alimento enteral, tristemente conocido en Chile $^{3}$.

\footnotetext{
${ }^{2}$ Confróntese inc. $1^{\circ}$ del art. 49 de la Ley № 19.496, de 1997, sobre protección de los derechos de los consumidores.

${ }^{3}$ Caso Contergan (Tribunal del Land Aquisgrán, JZ 1971, pp. 507 y ss.), caso de la colza (STS de 23 de abril de 1992, pp. 8827 y ss.) y caso del alimento enteral (sentencia del Tribunal de Juicio Oral en lo Penal de San Bernardo, RUC 0800102576-8, RIT 38-2011, de 24 de agosto de 2012).
} 
La responsabilidad penal del fabricante puede fundarse tanto en delitos de lesión (arts. $391 \mathrm{~N}^{0}$ 2, 399 y $494 \mathrm{~N}^{0} 5$ del CP , a título doloso o culposo, dado el caso) como en delitos de peligro (arts. 313 d, 314 y 315 del Código Penal). Mientras estos últimos ilícitos captan penalmente la mera elaboración o colocación en el mercado de productos defectuosos, con la aptitud de crear riesgos para la vida o salud de los consumidores, los primeros requieren una afectación sustancial de estos bienes jurídicos, a través de la utilización del respectivo producto.

La circunstancia de que los delitos de los arts. 313 d, 314 y 315 del código punitivo no contemplen, como presupuesto típico, el acaecimiento de un resultado (y, con ello, puedan evitarse las cuestiones concernientes a la relación entre el defecto de un bien de consumo y los daños causados por este ${ }^{5}$ ), podría llevar a pensar que sus posibilidades de aplicación en los casos de responsabilidad por el producto son muy considerables. Empero, ello ha de descartarse: los objetos de la acción sobre los cuales recaen las acciones típicas de estos delitos de peligro se limitan a un número reducido de productos, en concreto: "sustancias medicinales" (art. $313 \mathrm{~d}$ del CP), "comestibles, aguas u otras bebidas" (art. 315 del CP) u "otras sustancias peligrosas para la salud" (art. 314 del CP), refiriéndose esta última expresión únicamente a elementos que pueden causar un perjuicio al organismo humano a través de efectos de naturaleza química o químico-física ${ }^{6}$. De este modo, los peligros para la vida y salud surgidos, por ejemplo, de la comercialización de juguetes, electrodomésticos, herramientas de trabajo, robots o automóviles, todos ellos defectuosos, no quedan comprendidos por los ilícitos referidos. En cambio, como los delitos de homicidio simple,

\footnotetext{
${ }^{4}$ Si bien no es posible descartar en un caso de responsabilidad por el producto la comisión de un delito de homicidio calificado por medio de veneno (art. $391 \mathrm{~N}^{\circ} 1^{\circ}$, circunstancia tercera, del CP), de castración (art. 395 del CP), de mutilaciones (art. 396 del CP) o de administración de sustancias o bebidas nocivas (art. 398 del CP), esto no será lo más frecuente, puesto que difícilmente el fabricante actuará con dolo directo. Por otra parte, el delito de lesiones graves (art. 397 del CP) habrá de descartarse en supuestos de daños a la salud causados por productos defectuosos, porque las posibles conductas reprochables del fabricante, consistentes en colocar en el mercado productos peligrosos o no retirar del mercado tales bienes, en ningún caso podrán subsumirse en las acciones típicas de herir, golpear o maltratar de obra a otro.

${ }^{5}$ Acerca del problema relativo al vínculo causal entre la colocación en el mercado de un producto defectuoso (o su no retiro del mercado) y los daños a la vida o salud de los consumidores, entre otros, Hernández (2006), pp. 8 y ss.; Kaufmann (1971), pp. 572 y ss.; KuHLen (2015), números marginales 49 y ss.

${ }^{6}$ Así se desprende, por lo demás, de los ejemplos que la doctrina ha entregado de "otras sustancias peligrosas para la salud", al aludir a cosméticos, perfumes, insecticidas y pesticidas, ETCHEBERRY (1997), p. 288. De esta forma, quedan fuera del ámbito de aplicación del tipo aquellos elementos que solo pueden dañar la vida o salud a través de la interacción física con el cuerpo humano, como aparatos eléctricos o automóviles defectuosos, por ejemplo.
} 
lesiones menos graves y lesiones leves (sean dolosos o culposos, dado el caso) no contienen ningún elemento típico que restrinja la clase de producto cuya elaboración y venta puede causar una muerte o lesión corporal, estos ilícitos pasan a desempeñar un papel muy relevante para hacer efectiva la responsabilidad criminal del fabricante.

\section{El quebrantamiento de un deber jurídico como presupuesto básico de la responsabilidad penal del fabricante por los delitos de homicidio simple, lesiones menos graves y lesiones leves}

Tal como ocurre con el resto de las disposiciones del ordenamiento secundario de sanción, la aplicación de los tipos de homicidio simple, lesiones menos graves o lesiones leves persigue confirmar la vigencia de determinados deberes de conducta quebrantados por el autor $y$, con ello, conjurar el peligro de erosión de la norma lesionada ${ }^{7}$. Por eso, estos tipos penales solo adquieren relevancia frente a comportamientos que se hayan desviado de las exigencias del derecho, o sea, que puedan calificarse como jurídicamente desaprobados. De este modo, el presupuesto básico para sancionar al fabricante en virtud de los arts. $391 \mathrm{~N}^{\circ}$ 2, 399 o 494 № 5 del CP (a título doloso o culposo, según las circunstancias) consiste en que aquel haya infringido una norma de comportamiento (es decir, un deber jurídico) ${ }^{8}$. Esta norma puede revestir la forma de una prohibición o de un mandato y su finalidad es la protección de la vida y salud individual de los consumidores ${ }^{9}$. El quebrantamiento por parte del fabricante de la norma de comportamiento -"no emplee talidomida en medicamentos destinados a mujeres embarazadas", "retire del mercado el automóvil si sus frenos operan defectuosamente", etc.- crea riesgos desaprobados para bienes jurídicos.

\footnotetext{
7 Sobre el cometido que desempeñan las normas de sanción penales, recientemente, Freund (2015), p. 148; FRISCH (2014), pp. 16 y ss.; TIMM (2012), p. 44.

${ }^{8}$ Sobre la infracción de una norma de conducta como presupuesto básico de cualquier hecho punible, FRISCH (1983), pp. 59 y ss.; FRISCH (1993), p. 10.

${ }^{9}$ Acerca de la finalidad que persiguen las normas de comportamiento, consistente en la conservación de bienes jurídicos, entre otros, ApPel (1998), p. 453; Freund (2009), §1, número marginal 9; MurmanN (2017), § 8, número marginal 6; RojAs (2013), p. 98; Tıмм (2012), p. 42. Las únicas normas de comportamiento relevantes para fundar una responsabilidad penal del fabricante, por los delitos de homicidio simple, lesiones menos graves o lesiones leves, son aquellas destinadas a la protección de la vida y salud de los consumidores. Como los bienes jurídicos que tales delitos protegen en forma indirecta son precisamente la vida y salud, solo la infracción de normas de conducta que busquen eliminar o minimizar los peligros para estos bienes puede entrar en consideración para fundar una responsabilidad penal por los delitos referidos. Por eso, y a modo de ejemplo, las normas de conducta previstas en la Ley $\mathrm{N}^{\circ} 19.039$, de Propiedad Industrial, vinculadas con la protección de esta clase de propiedad y que el fabricante pueda quebrantar, no juegan ningún rol para fundar una responsabilidad penal por los delitos de homicidio o lesiones en perjuicio de los consumidores.
} 
Imponer una sanción criminal al productor, sin que este haya infringido una norma de conducta establecida para la protección de la vida y salud de los consumidores, no solo sería injusto, sino también ilegítimo desde el punto de vista de la finalidad que ha de cumplir la pena. Ciertamente, un comportamiento que no ha quebrantado ningún deber jurídico merece ser confirmado -y no desaprobado- por el derecho; además, sin la lesión a un deber jurídico, no hay cuestionamiento de su vigencia y, con ello, se vuelve totalmente innecesaria la reacción del Estado a través de la pena ${ }^{10}$.

Ahora bien, los precisos deberes jurídicos que el fabricante de bienes de consumo ha de cumplir, para no verse expuesto a la imposición de una pena criminal, no se encuentran contenidos en los tipos de homicidio y lesiones aplicables a los casos de responsabilidad por el producto ${ }^{11}$. Expresiones tales como "mate a otro" (art. 391 del CP) o "lesiones no comprendidas en los artículos precedentes" (art. 399 del CP) pueden interpretarse, en el mejor de los casos, como prohibiciones generales de causación de resultados. De semejantes prohibiciones no se desprenden directrices precisas que permitan al fabricante tomar decisiones jurídicas correctas frente a los riesgos del producto. Del tenor de dichos arts. 391 o 399, el fabricante solo puede deducir qué resultados lesivos en perjuicio de los consumidores ha de evitar, pero no cómo evitarlos ${ }^{12}$. Para el juez penal, que ha de establecer si el productor ha infringido o no las exigencias del derecho, las normas en cuestión tampoco entregan orientación clara.

En razón de lo planteado, parece fundamental reflexionar acerca de cuáles son los deberes jurídicos que un fabricante de productos ha de observar para que su conducta no cree riesgos desaprobados, en relación con la vida y salud de los consumidores, y no se vea expuesto a responsabilidad criminal ${ }^{13}$.

10 FreUnd (2009), § 2, número marginal 8; FrISCH (1996a), p. 145.

${ }^{11} \mathrm{Y}$ es que la función de estos tipos no consiste en establecer prohibiciones o mandatos que puedan servir de pauta de conducta al ciudadano, sino en formular aquellos presupuestos bajo los cuales el juez ha de sancionar un comportamiento contrario a deber. Así lo destacan Freund (2009), §1, números marginales 12 y 34; FrISCH (1983), p. 59; MaÑaLICH (2010), pp. 172 y ss.

12 Reus (2010), p. 83.

${ }^{13}$ La determinación de los deberes jurídicos que un fabricante tiene que cumplir supone, entonces, una labor de concreción del derecho. Los delitos de resultado (como los de homicidio o lesiones menos graves) son tipos penales "abiertos", es decir, normas de sanción que están legalmente descritas solo de un modo parcial y respecto de las cuales necesariamente hay que desplegar un proceso hermenéutico, para así delinear los contornos específicos de la respectiva conducta punible. El que los delitos de resultado constituyan tipos "abiertos" suele destacarse únicamente respecto de los ilícitos de resultado culposos; así, por ejemplo, CuRy (2005), p. 334. Pero lo mismo cabe decir de los delitos de resultado dolosos, puesto que, también en estos, el intérprete se ve enfrentado a una tarea de concreción del comportamiento típico (que es precisamente el objeto del dolo). En la medida en que el respectivo tipo "abierto" contenga el núcleo fundamental de la materia de la prohibición (como acontece tratándose de 
Como ya hemos planteado anteriormente en otro trabajo ${ }^{14}$, el punto de partida de cualquier consideración sobre los deberes jurídicos del fabricante lo constituye la siguiente idea: nadie puede ejercer su libertad garantizada jurídicamente sin tener en consideración los derechos y bienes de los demás ${ }^{15}$. El presupuesto inmanente del reconocimiento al individuo de la libertad de acción lo constituye, precisamente, la prohibición de afectar durante su ejercicio a los restantes miembros de la comunidad ${ }^{16}$. En la configuración de su propia vida, los individuos deben poder confiar en que los otros -así como ellos mismos- acatarán tal prohibición; su infracción masiva tornaría imposible la vida en sociedad ${ }^{17}$.

Por consiguiente, el fabricante solo puede ejercer su libertad económica bajo la condición de que coloque productos en el mercado que no pongan en peligro la vida o salud del consumidor, en caso de ser utilizados de acuerdo con la finalidad a la que están destinados, o de un modo racionalmente previsible ${ }^{18}$. Por uso conforme a la finalidad del producto debemos entender aquel uso que se

los delitos de homicidio y lesiones en la legislación chilena), no se presentarán problemas en relación con el principio de legalidad; Bustos y Hormazábal (1997), p. 93.

14 Contreras (2015), pp. 273 y ss.

15 Al respecto, FrISCH (2011), pp. 428 y ss.; JAKOBS (1991), sección 28, número marginal 14, y sección 29, números marginales 29 y ss.; KÖHLER (2006), pp. 257 y ss.

16 Así, FrISCH (2011), p. 429, con más referencias.

17 ZACZYK (1989), p. 212.

18 Esta obligación del fabricante se refleja, por ejemplo, en el art. $4^{\circ}$ del Reglamento chileno sobre seguridad de los juguetes, según el cual los juguetes deberán ser seguros para los usuarios en circunstancias de uso normal o razonablemente previsible. Véase también, en el derecho español, el art. $4^{\circ}$ párrafo $1^{\circ}$, en relación con el art. $2^{\circ}$ letra a), ambos del Real Decreto sobre seguridad general de los productos, conforme al cual los fabricantes tienen el deber de poner en el mercado únicamente productos seguros, entendiéndose por tales aquellos que, en condiciones de utilización normales o razonablemente previsibles, no presentan riesgo alguno o únicamente riesgos mínimos. Para BARRIENTOS (2010), p. 11, a la hora de fijar las medidas de seguridad del producto, el fabricante tiene que examinar las condiciones normales de utilización del bien, pero también las anormales que sean razonablemente previsibles. Por otra parte, del art. 20 letra c) de la Ley $\mathrm{N}^{\circ}$ 19.496, sobre protección de los derechos de los consumidores, no puede desprenderse que el fabricante solo esté obligado a comercializar productos seguros en caso de empleo de acuerdo con la finalidad a la que están destinados ["uso o consumo al que está destinado", en los términos de dicha letra c)], y no en caso de empleo racionalmente previsible. Y es que el art. 20 de la Ley $N^{\circ} 19.496$ no contiene un catálogo exhaustivo de deberes jurídicos relativos a la seguridad de los productos que un fabricante tenga que cumplir, sino que alude (simplemente) a la garantía legal o derecho de opción del consumidor. En virtud de dicha garantía, el consumidor está facultado para optar (cuando la cosa comprada no es apta para su uso o consumo, por ejemplo, entre la reparación gratuita del bien o, previa restitución, su reposición o la devolución de la cantidad pagada. En detalle sobre el art. 20 letra c) de la Ley No 19.496, Barrientos (2016), pp. 156 y ss. 
ajusta a su normal destino; el empleo racionalmente previsible, por su parte, es aquella utilización que cualquier persona juiciosa podría darle a un producto ${ }^{19}$.

El deber básico del fabricante consistente en la prohibición de colocar en el mercado productos inseguros en caso de utilización de acuerdo con su finalidad, o de una manera racionalmente previsible, permite a los consumidores confiar en la inocuidad del producto, liberándolos de la pesada carga de verificar por sí mismos su carácter seguro ${ }^{20}$. Con ello no solo se crea un amplio espacio de desarrollo de libertad para el consumidor, sino que, además, se facilita en favor del fabricante la venta de productos "dignos de confianza"21.

Ahora bien, a pesar de la gran relevancia del deber de conducta consistente en no colocar en el mercado productos que sean inseguros en caso de utilización de acuerdo con su finalidad, o de un modo racionalmente previsible, este deber no ha sido objeto de un análisis dogmático en el derecho chileno, que permita aclarar su contenido. El presente artículo pretende constituir un primer aporte en este sentido. Para esta tarea, se tendrá a la vista, fundamentalmente, la jurisprudencia y doctrina alemanas, que se ocupan hace décadas de la responsabilidad jurídica del fabricante.

\section{La prohibición de colocar en el mercado productos peligrosos y los defectos de diseño, fabricación e instrucción}

El fabricante infringe la prohibición de colocar en el mercado productos que sean peligrosos ${ }^{22}$ en caso de utilización de acuerdo con su finalidad, o de un modo racionalmente previsible, cuando no los diseña cuidadosamente, cuando los fabrica de un modo negligente, o bien cuando no los dota de las

\footnotetext{
${ }^{19}$ Más detalladamente sobre el significado de "uso conforme a la finalidad a la que está destinado el producto" y "uso del producto razonablemente previsible" véase el apartado 3.1.2, "Los riesgos del producto que han de ser reconocidos".

20 En este sentido, Freund (1992), p. 219.

${ }^{21}$ Freund (1992), p. 219.

${ }^{22}$ En el derecho civil es frecuente la distinción entre "producto defectuoso" y "producto peligroso". El "producto defectuoso" sería aquel "que no ofrece la seguridad que el consumidor o usuario puede legítimamente esperar en cuanto a la protección de su vida, su salud o las cosas del patrimonio diversas del producto que adolece del defecto", mientras que el "producto peligroso" correspondería a aquel "que por sí mismo presenta riesgos en su utilización, pero que no necesariamente es inseguro si se ofrecen advertencias sobre la forma en que debe ser correctamente manipulado para evitar que cause daño"; así lo destaca, entre otros, CORRAL (2011), p. 110. Sin perjuicio de que esta diferenciación está muy extendida en el campo del derecho civil, pareciera aportar más confusión que claridad en el ámbito del derecho penal. Y es que todo producto, dependiendo de sus características y forma específica de empleo, puede representar un riesgo para los bienes jurídicos de los consumidores o usuarios; en ese sentido, todo producto puede calificarse como "peligroso". Lo único relevante, entonces, es si los riesgos vinculados con su uso han de ser considerados como jurídicamente tolerados o desaprobados.
} 
instrucciones necesarias para un manejo seguro; es decir, cuando los productos adolecen de defectos de diseño, fabricación o instrucción, respectivamente ${ }^{23}$. Los defectos de diseño existen cuando la concepción original de un producto se sitúa bajo los estándares de seguridad que permiten su utilización segura ${ }^{24}$; así ocurrirá, por ejemplo, cuando en el diseño de un juguete para niños de corta edad se contemple la incorporación de piezas que puedan provocar cortes en las manos. Los defectos de fabricación, por su parte, tienen su origen en la fase de elaboración misma del producto, de modo tal que su nivel de seguridad no coincide con aquel previsto en el diseño o concepción original ${ }^{25}$; este tipo de defectos aparecerán, por ejemplo, cuando se verifique un error en el proceso de ensamblaje de las partes de un automóvil. Finalmente, los errores de instrucción se presentan cuando faltan las necesarias advertencias de uso, o cuando estas son incorrectas ${ }^{26}$; por ejemplo, cuando en el prospecto de un medicamento se omite informar acerca de un grave efecto secundario.

En las páginas siguientes se intentará responder a la pregunta: ¿cómo puede el fabricante reconocer y evitar los mencionados defectos de diseño, fabricación e instrucción? Para ello, es necesario distinguir entre dos clases de productos: por una parte, aquellos que el fabricante quiere colocar por primera vez en el mercado (productos que corresponden a "nuevos desarrollos", a continuación, 3) y, por otra parte, los bienes de consumo que ya han sido colocados en el mercado y que el fabricante desea seguir produciendo y distribuyendo (al respecto, infra 4).

\section{Productos que corresponden a "nuevos desarrollos"}

Por productos que corresponden a "nuevos desarrollos", debemos entender aquellos bienes de consumo que no han sido colocados antes en el mercado, y que el fabricante quiere elaborar y comercializar por primera vez. Piénsese en nuevos tipos de alimentos procesados, medicamentos, sustancias químicas, herramientas o máquinas para ejecutar ciertos trabajos, etc., nunca antes diseñados o fabricados por el productor o la competencia. En relación con los riesgos para la vida y salud que puede conllevar la utilización de estos nuevos bienes de consumo, el fabricante está obligado a cumplir con dos deberes jurídicos

\footnotetext{
${ }^{23}$ Sobre los diferentes tipos de defectos en el ámbito de la responsabilidad civil por el producto, BARROS (2013), p. 754; CORRAL (2011), p. 215.

${ }^{24}$ Foerste (2012b), número marginal 71; HaGer (2009), número marginal F 12; ISLeR (2013), p. 124.

25 Así lo destaca Foerste (2012b), número marginal 177.

${ }^{26}$ HaGer (2009), número marginal F 14; Salvador y Ramos (2008), p. 189.
} 
elementales: el deber de reconocimiento y el deber de reducción de riesgos ${ }^{27}$. Así, el fabricante está obligado, por una parte, a reconocer y evaluar correctamente los riesgos vinculados al uso conforme a la finalidad del producto o al uso racionalmente previsible del mismo (a continuación, 3.1). Por otra parte, tiene la obligación de adoptar las medidas necesarias para reducir o excluir tales peligros (al respecto, infra 3.2.).

\subsection{Deber de reconocimiento de riesgos del producto}

Para estar en condiciones de evitar afectaciones a los bienes jurídicos de los consumidores, en el sentido de los delitos de homicidio o lesiones, el fabricante tiene que saber qué riesgos surgen de su producto: la reconocibilidad del peligro es el presupuesto necesario para su reducción ${ }^{28}$. Por este motivo, el derecho impone al productor el deber jurídico de reconocer o identificar los riesgos potenciales vinculados con el uso del bien que pretende introducir en el mercado.

Tanto reglas de carácter extrapenal referidas a la seguridad de productos -contenidas en leyes o reglamentos- como extrajurídicas - previstas en reglas técnicas- pueden facilitar al fabricante la tarea de reconocer los riesgos del producto. Tales reglas se basan usualmente en la experiencia acumulada en un determinado sector, e indican aquellos peligros vinculados con el uso de productos de determinadas características ${ }^{29}$. Así, por ejemplo, los límites fijados en reglas extrapenales para la ionización de alimentos permiten identificar

\footnotetext{
${ }^{27}$ Los deberes de reconocimiento y de reducción de peligros son tratados normalmente en el contexto de los delitos culposos de resultado, hablándose del cuidado "interno" y "externo". Por todos, véase HeRnández (2011), p. 110; JesCHeCK y Weigend (1996), pp. 578 y ss.; Wessels et al. (2017), número marginal 942. Sin embargo, tales deberes también se pueden quebrantar en forma dolosa. Eso ocurrirá cuando el sujeto capte de manera completa la dimensión de injusto relevante de su conducta -que se aparta de lo ordenado en el respectivo deber de reconocimiento o de reducción de peligros- $y$, pese a ello, la lleve a cabo o la omita [acerca de este entendimiento del dolo, FrISCH (1983), pp. 94 y ss., 118 y ss. y 210 y ss.]. Así, un fabricante infringirá dolosamente su deber de reconocimiento de peligros cuando, por ejemplo, no lleve a cabo de un modo consciente un test indispensable para identificar los riesgos del producto, de modo tal que para él la dimensión del peligro del bien de consumo que pretende comercializar se convierte en algo totalmente incierto, sin tener ningún punto de apoyo que le permita confiar en que el resultado lesivo no acaecerá. Una infracción dolosa de los deberes de reducción de peligros tendrá lugar, por ejemplo, cuando un fabricante de alimentos los coloque en el mercado a pesar de saber que están contaminados con sustancias nocivas para la salud, capaces de lesionar a un consumidor.

28 DeUtsch (1995), p. 94; LoRenz (1965), p. 85; antes de ellos ya EXner (1910), p. 138 ("la evitabilidad está condicionada por la previsibilidad"), y ENGISCH (1930), pp. 365 y ss.

${ }^{29}$ BGHST 4, 182, 185; 12, 75, 78; Tribunal Superior del Land Karlsruhe NStZ-RR 2000, 141, 142; KüHL (2017), § 17, número marginal 23.
} 
fácilmente los riesgos para la salud que trae consigo el consumo de comestibles sometidos a altos niveles de radiación ${ }^{30}$.

Antes de analizar en detalle las principales cuestiones vinculadas a los deberes de reconocimiento de los riesgos del producto, conviene aclarar qué importancia tiene el criterio de la reconocibilidad para la configuración de los deberes jurídicos del fabricante.

\subsubsection{Consideraciones generales acerca del criterio de la reconocibilidad}

Una norma cuyo cometido sea la protección de bienes jurídicos, ejerciendo influencia en el comportamiento de los sujetos, perdería todo sentido y legitimidad si sus potenciales destinatarios, a pesar de su total disposición a acatarla, no tuvieran ninguna posibilidad fáctica de cumplirla (ultra posse nemo obligatur) ${ }^{31}$. Si los potenciales destinatarios no reconocen las concretas probabilidades de daño de su conducta, y esa errónea apreciación se funda en un error inevitable, no resulta exigible un comportamiento diverso ${ }^{32}$. Los peligros que no pueden ser reconocidos por el sujeto -ni aun aplicando el cuidado debido- no juegan ningún rol en la reflexión general concerniente a la forma que tiene que adoptar una conducta para así prevenir cursos causales lesivos ${ }^{33}$.

La reconocibilidad no es un elemento exclusivo de los delitos imprudentes, en cuyo seno fue originalmente tratada, sino que constituye una exigencia que ha de cumplir cualquier hecho punible ${ }^{34}$. Tanto el delito doloso como el negligente están marcados por las exigencias de la reconocibilidad (y la evitabilidad) de la realización del tipo. En el caso del dolo, la reconocibilidad llega a constituir conocimiento; en el caso de la culpa, no ${ }^{35}$. Por eso, la reconocibilidad de la realización del tipo es un criterio fundamental para la configuración de cualquier deber de conducta; en la determinación de un deber jurídico, el individuo únicamente ha de contar con aquellos cursos dañosos que sean reconocibles según la experiencia de vida o profesional.

En consecuencia, para precisar la forma que ha de adoptar el diseño, la fabricación o las instrucciones de un producto, basta con que el fabricante

\footnotetext{
${ }^{30}$ Véase la Resolución Exenta № 636 de 21.08.2014, del Ministerio de Salud, publicada en el Diario Oficial el 6.09.2014, que establece dosis máximas de irradiación de alimentos.

31 FREUND (1992), pp. 36 y ss.

32 Así lo destaca Timm (2012), p. 67.

33 Sternberg-Lieben y Schuster (2014), número marginal 125.

${ }^{34}$ Así lo evidencian Corcor (1989), p. 227; Freund (2009), § 5, número marginal 42 y ss.; Kremer-Bax (1999), p. 45.

35 JаковS (1991), sección 9, número marginal 4.
} 
considere aquellos peligros que queden abarcados por la experiencia de vida o profesional. De acuerdo con esta, es previsible, por ejemplo, que caramelos de cierto tamaño queden atrapados en la garganta de niños muy pequeños, impidiéndoles respirar. Por eso, las golosinas que estén destinadas a niños de corta edad han de revestir características tales (en cuanto a volumen, consistencia, etc.) que su consumo no conlleve ningún riesgo de muerte por asfixia ${ }^{36}$.

La exigencia de reconocibilidad de los cursos lesivos fundamenta, desde un punto de vista material, por qué el fabricante no es responsable por los daños que tengan su origen en los denominados riesgos de desarrollo ${ }^{37}$. Estos representan peligros del producto que ni siquiera un fabricante diligente es capaz de reconocer-ni, por lo tanto, de evitar-, aplicando todo el cuidado exigible al momento de la introducción de los bienes en el mercado ${ }^{38}$. Así, por ejemplo, el efecto carcinógeno de un medicamento para tratar la epilepsia puede manifestarse únicamente años después de su primera comercialización, debido a que el tipo de cáncer que provoca solo se desarrolla luego de un uso muy prolongado del producto, o bien porque las pruebas tóxico-farmacológicas o clínicas exigibles no permitieron en su momento hacer cognoscible el efecto carcinógeno ${ }^{39}$. Una norma de conducta que obligara al fabricante de medicamentos a evitar peligros semejantes, no reconocibles desde una perspectiva ex ante, no sería compatible con un orden primario que pretende influir en el comportamiento de los sujetos, con vistas a una efectiva conservación de bienes jurídicos ${ }^{40}$.

\footnotetext{
${ }^{36}$ STS de 10 de junio de 2002, pp. 11028 y ss.

${ }^{37}$ La Ley N N 19.496, sobre protección de los derechos de los consumidores, excluye la responsabilidad civil por tales riesgos (art. 47, inciso segundo). Distinto es el régimen tratándose de productos sanitarios defectuosos; según el art. $111 \mathrm{~K}$ del Código Sanitario, el fabricante de tales productos no puede eximirse de responsabilidad alegando que los daños tienen su origen en hechos o circunstancias "que no se previeron según el estado de los conocimientos científicos o técnicos existentes en el momento de su puesta en circulación o uso". En detalle sobre los riesgos de desarrollo en el derecho alemán, BGHz 51, 91, 105; 80, 186, 190 s.; BODEWIG (1999), pp. 269 y ss., 277 y ss.; BORER (1986), pp. 74 y ss. Respecto del derecho chileno, Corral (2011), pp. 132, 238 y ss. En relación con el derecho español, Í́̃IGO (2001), pp. 232 y ss.

38 Así lo destaca MAYer (2008), pp. 278 y ss.

39 El ejemplo puede encontrarse en Foerste (2012b), número marginal 104.

${ }^{40}$ Es cierto que no es posible fundar una responsabilidad penal del fabricante por aquellos peligros del producto que -aun cumpliéndose con el cuidado debido- no pudieron ser reconocidos en el momento de su colocación en el mercado. Empero, la responsabilidad del fabricante no termina en el momento en que comercializa sus productos. A partir de la colocación en el mercado de los bienes de consumo, el fabricante tiene el deber jurídico de indagar e informarse acerca de los peligros "ocultos" del producto (los Ilamados riesgos de desarrollo); este corresponde al denominado deber de vigilancia. Al respecto, en detalle, Frick y KLUTH (2006), pp. 206 y ss.; MICHALSKI (1998), pp. 961 y ss. Si se descubren peligros "ocultos", puede ser necesaria una advertencia al consumidor o, incluso, la retirada del producto.
} 


\subsubsection{Los riesgos del producto que han de ser reconocidos}

Los riesgos vinculados con el uso de un producto que el fabricante tiene que reconocer, para así lograr una adecuada protección de la vida y salud de los consumidores, son extremadamente variados. Así queda en evidencia si se tienen a la vista los casos más importantes de responsabilidad por el producto del derecho alemán y español, referidos a los más diversos tipos de peligro:

- Riesgos de electrocución de adaptadores sin conexión a tierra ${ }^{41}$.

- Riesgo de grave envenenamiento por el consumo de vino mezclado con sustancias tóxicas ${ }^{42}$.

- Riesgo de malformaciones en embriones humanos, debido a la utilización de medicamentos que contienen talidomida ${ }^{43}$.

- Riesgo de graves accidentes automovilísticos, debido al desprendimiento de la cubierta de neumáticos defectuosamente diseñados ${ }^{44}$.

- Riesgo de envenenamiento mortal por el consumo de aceite de mesa desnaturalizado con anilina ${ }^{45}$.

Las situaciones de peligro vinculadas con el uso de un producto pueden tener su origen inmediato en determinadas cualidades inseguras de este, en las instrucciones deficientes que lo acompañan, en determinadas características de las personas que entrarán en contacto con el bien de consumo, o en ciertos efectos riesgosos que se generan cuando el producto es empleado junto a otros ${ }^{46}$. De especial interés son estas dos últimas circunstancias. De esta forma, una evaluación correcta de los peligros del producto solo es posible si el fabricante tiene en consideración el círculo de usuarios que directamente lo utilizarán (ancianos, consumidores que padecen ciertas enfermedades, personal especializado, etc.) o el tipo de personas que, en calidad de "terceros", podrían también resultar afectadas por los riesgos del bien de consumo. Un ejemplo sobre esto último: la experiencia muestra que los niños juegan a menudo cerca de puertas de garajes; si un fabricante quiere colocar en el mercado un nuevo tipo de tales puertas, deberá considerar en el diseño del producto los peligros de lesiones provocadas por el aprisionamiento de extremidades de niños ${ }^{47}$. Por otra parte,

41 BGH, 1 StR 618/58, reproducida en SCHMidT-SAlzer (1982), pp. 170 y ss.

42 Sts de 22 de abril de 1987, pp. 2434 y ss.

43 Tribunal del Land Aquisgrán, JZ 1971, pp. 507 y ss.

44 Tribunal del Land Múnich II, reproducida en SCHMidT-SAlzer (1982), pp. 296 y ss.

45 Sts de 23 de abril de 1992, pp. 8827 y ss.

46 Este catálogo de las fuentes de riesgo de los productos de consumo se desprende de lo dispuesto en el parágrafo 3, párrafo 2, de la ley de seguridad de productos alemana (Produktsicherheitsgesetz - ProdSG).

47 SChmidt-Salzer (1990), número marginal 4.875. 
para un correcto reconocimiento de riesgos, hay que tener en cuenta que muchos productos pueden desplegar sus efectos en un ámbito caracterizado por la existencia de otros bienes de consumo ${ }^{48}$. El uso combinado de unos y otros puede dar origen a riesgos importantes para la vida o salud individual, en el

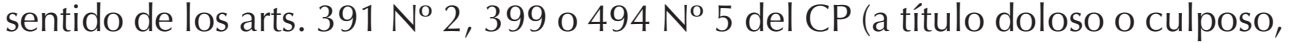
según las circunstancias). Piénsese, por ejemplo, en determinadas motocicletas, cuya estabilidad puede verse seriamente afectada en caso de que sean equipadas con accesorios para manubrios o con portaequipajes de cierto volumen ${ }^{49}$. Ahora bien, el fabricante está obligado a reconocer aquellos peligros que pueden surgir del uso del producto en caso de que este sea utilizado de acuerdo con su finalidad, pero también en caso de que sea empleado al margen de ella, en la medida en que este uso pueda considerarse racionalmente previsible o "socialmente habitual". Como se dijo, el empleo del producto de acuerdo con su finalidad es aquel uso que corresponde al normal destino del bien; este se fija teniendo en cuenta tanto las expectativas que puedan tener los consumidores acerca de las formas de empleo del producto, como las indicaciones que al respecto entregue el propio fabricante ${ }^{50}$. De este modo, es relevante indagar cuál es el uso natural que le daría al producto un consumidor promedio, y si ese uso se amplía o restringe a través de las instrucciones, advertencias e informaciones que entrega el propio fabricante al consumidor ${ }^{51}$. Ejemplos de empleo del producto de acuerdo con su finalidad son la utilización de biberones para proporcionar líquidos a niños de muy corta edad o el uso de hornos de microondas para calentar alimentos. Por su parte, el uso incorrecto del producto de carácter racionalmente previsible o "socialmente habitual" es aquel uso del producto que queda al margen de su normal destino, pero en el cual también una persona juiciosa incurriría. Como también un consumidor sensato, que no se quiere exponer a riesgos innecesarios, puede, dado el caso, utilizar el producto de esa forma, el fabricante está obligado a prever aquellos peligros que tienen su origen en ese tipo de uso ${ }^{52}$. Así, por ejemplo, un fabricante de medicamentos debe contar con que, tratándose de ciertos fármacos que son empleados en

48 KLINDT (2007), § 4, número marginal 44.

49 BGH NJw 1987, pp. 1009 y ss.; SCHMidt-SAlzer (1990), número marginal 4.878.

50 Holst (2006), p. 41.

51 Foerste (2012b), número marginal 81.

52 También un fabricante como (potencial) consumidor podría usar un producto fuera de la finalidad que le es propia, pero de un modo sensato. El deber de reconocer los peligros que pueden surgir de un uso incorrecto del producto, pero de carácter racionalmente previsible o "socialmente habitual", aparece, entonces, tanto desde el punto de vista del consumidor como del fabricante (es decir: recíprocamente) como razonable. Acerca de la capacidad de aceptación recíproca como método para la concreción de 
situaciones dramáticas como, por ejemplo, inhaladores para combatir ataques de asma, los pacientes no reaccionen de un modo controlado, sino dominados por el miedo y la desesperación, y es posible que se apliquen dosis del producto mucho mayores que las indicadas por el respectivo médico ${ }^{53}$. En consecuencia, sobre el fabricante de tales medicamentos pesa el deber jurídico de advertir muy claramente de los riesgos de intoxicación en caso de sobredosis.

El uso incorrecto del producto de carácter racionalmente previsible o "socialmente habitual" tiene que distinguirse del uso incorrecto que no reviste tal carácter, es decir, del empleo incorrecto e irraciona $/ 54$, cuyos riesgos el fabricante no tiene el deber jurídico de reconocer. Un ejemplo de empleo incorrecto e irracional sería el transporte de una persona en el portaequipaje de una bicicleta (lo que implica el peligro de que el conductor no pueda frenar correctamente debido a una sobrecarga del vehículo). La delimitación entre el uso incorrecto racionalmente previsible o "socialmente habitual", por una parte, y el empleo incorrecto e irracional, por otra, es una cuestión compleja y tiene que hacerse recurriendo a un conjunto de criterios de diferenciación. En primer lugar, es necesario preguntarse qué uso del producto se puede esperar de acuerdo con la experiencia de vida o laboral general. Así, por ejemplo, según la experiencia de vida general no se puede esperar que el usuario de un secador de pelo -luego de extraer el concentrador de aire del aparato- lo presione en contra de su barbilla, causándose graves quemaduras ${ }^{55}$. Además, hay que atender a cuán lejano o cercano sea el uso incorrecto del producto respecto de su utilización de acuerdo con su finalidad; mientras más lejano sea el mal uso respecto del fin natural al que debe destinarse el producto, más probable es que estemos frente a un empleo incorrecto e irracional ${ }^{56}$. Finalmente, el grado de responsabilidad que el consumidor tiene en el daño causado por el uso inapropiado del producto, así como la frecuencia estadística de la utilización indebida constituyen otros criterios que permiten distinguir entre un uso incorrecto racionalmente previsible o "socialmente habitual", por una parte, y un empleo incorrecto e irracional, por otra ${ }^{57}$.

los deberes jurídicos del fabricante, véase apartado 3.2.3.3, "El principio de proporcionalidad como criterio para concretar los deberes de reducción de riesgos".

53 BGHz 106, 273, 281.

${ }^{54}$ Contreras (2018), pp. 125 y ss.

55 Tribunal del Land Frankfurt/Main, NJW-RR 1986, 658, 659.

${ }^{56}$ HOLST (2006), p. 48.

57 Holst (2006), p. 48; Holtermann (2007), p. 129. 


\subsubsection{Base de conocimiento para la reconocibilidad}

La base de conocimiento mediante la cual se pueden identificar, o reconocer, los peligros vinculados con el uso de productos que corresponden a "nuevos desarrollos" está constituida por los conocimientos científicos y técnicos existentes ${ }^{58}$, así como por la experiencia acumulada en el respectivo sector productivo. La mayoría de las veces, el fabricante tiene incorporados conocimientos y experiencias en relación con peligros de productos que ya se encuentran disponibles en el mercado y que tienen características similares a los "nuevos" bienes de consumo que se pretenden comercializar por primera vez. Por lo anterior, el problema de la reconocibilidad de los riesgos que pueden surgir de productos que corresponden a "nuevos desarrollos" es menos grave de lo que podría parecer a primera vista. Ejemplo: para reconocer aquellos peligros para la vida y salud individual que pueden surgir del empleo de un nuevo tipo de neumático para automóviles fabricado con sílice, el productor puede tener en consideración aquellos riesgos que surgen de la utilización de neumáticos tradicionales, producidos con negro de carbón (aparición a largo plazo de deformaciones en la superficie, desprendimiento de parte de esta, surgimiento de grietas, etc.).

Si en el caso particular falta una suficiente base de experiencia, o de conocimientos científicos o técnicos para reconocer los peligros de un producto correspondiente a un "nuevo desarrollo", entonces el fabricante está obligado a procurarse los conocimientos necesarios. Para ello, el productor debe indagar el correspondiente estado de la ciencia y de la técnica, obtener asesoría especializada $^{59} \mathrm{O}$, dado el caso, llevar a cabo las necesarias pruebas o ensayos ${ }^{60}$. Tratándose de ciertos productos - por ejemplo, medicamentos ${ }^{61}-$, el orden primario obliga expresamente al fabricante a realizar estudios para identificar los peligros de los bienes que pretende introducir en el mercado ${ }^{62}$.

\footnotetext{
58 Por conocimientos científicos y técnicos existentes debemos entender aquellas nociones o saberes de que se dispone en un determinado momento, y que surgen de disciplinas científicas o técnicas. La expresión "conocimientos científicos y técnicos" no es ajena a nuestro derecho (véase, por ejemplo, el art. $111 \mathrm{~K}$ del Código Sanitario).

59 Sobre este punto, Schmidt-Salzer (1990), número marginal 4.777.

60 SCHMidt-SAlzer (1990), número marginal 4.748.

${ }^{61}$ Artículo 36, número 1, del Reglamento del sistema nacional de control de los productos farmacéuticos de uso humano.

${ }^{62}$ La infracción del deber de realizar pruebas o ensayos para identificar con exactitud los peligros del producto ofrece problemas cuando se trata de hacer efectiva la responsabilidad del fabricante a través de los delitos de homicidio o lesiones consumados (arts. $391 \mathrm{~N}^{\circ} 2$, 399 y $494 \mathrm{~N}^{\circ} 5$ del CP). Y es que esto supone demostrar que el correspondiente resultado de muerte o lesión corporal no habría tenido lugar con una probabilidad rayana en la certeza, o con una probabilidad preponderante, de haberse
} 


\subsection{Deber de reducción de riesgos del producto}

\subsubsection{Cuestiones preliminares}

$\mathrm{Si}$, cumpliendo con sus deberes de reconocimiento de peligros, el fabricante advierte que un nuevo producto trae consigo determinados riesgos para la vida y salud de los consumidores, entonces está obligado a adoptar las respectivas medidas de reducción de peligros.

Ahora bien, exigir al fabricante la completa exclusión de los riesgos del producto no sería razonable, teniendo en cuenta los intereses de los propios consumidores. Y es que debido a las dificultades técnicas, y a los altos costos, que traería aparejada la adopción de medidas de seguridad capaces de excluir la totalidad de los riesgos del producto, los consumidores se verían privados, muy probablemente, de productos a los que quieren acceder. Así, por ejemplo, exigir únicamente la fabricación de secadores de pelo que no causen ningún choque eléctrico en caso de que caigan por descuido en una bañera llena de agua, afectaría el interés en el ejercicio de la libertad de los propios consumidores. El cumplimiento de una exigencia semejante sería, seguramente, impracticable desde el punto de vista técnico o, en el mejor de los casos, elevaría los costos del producto hasta un punto tal que un importante número de consumidores tendría que renunciar a su compra. Frente al problema de la configuración de un deber jurídico, nunca se puede olvidar que el trasfondo y el presupuesto de toda prohibición de conductas, desplegadas por terceros, es el interés de los eventualmente afectados en sus bienes jurídicos por estas conductas, en su no realización ${ }^{63}$. La consideración de ese interés es fundamental para dotar de contornos específicos a cualquier deber jurídico. En relación con las conductas creadoras de riesgos de los demás, el interés de los individuos no consiste en que no se generen peligros de cualquier tipo o magnitud (algo semejante Ilevaría a una paralización de la vida social), sino en que no se creen aquellos tipos de peligros a los cuales personas juiciosas no se expondrían, para así evitar un daño en sus bienes jurídicos ${ }^{64}$. En el ámbito de la responsabilidad jurídica

\footnotetext{
cumplido con el deber de ejecutar pruebas o ensayos. Teniendo en cuenta la complejidad de los riesgos que pueden surgir de un producto, será normalmente difícil establecer esa relación de contrariedad al deber. Si no se admite una imputación de resultados sobre la base únicamente de la teoría del incremento del riesgo, entonces debería negarse la responsabilidad penal por un delito imprudente o por un delito doloso consumado. Respecto al estado de la discusión actual sobre la teoría del incremento del riesgo, PuPPE (2017), números marginales 135 y ss.

${ }^{63}$ FRISCH (1992), p. 6.

${ }^{64}$ Acerca de la idea de que a los sujetos les está prohibido crear aquellos riesgos a los que una persona sensata no se expondría, FrISCH (1988), pp. 128 y ss., 138 y ss.; FRISCH (2012), pp. 65 y 72 . Una idea similar se puede encontrar en la STS de 23 de abril de 1992, p. 8875 -caso de la colza-, según la cual
} 
del fabricante, lo anterior significa: los consumidores no están interesados en productos cuya utilización no genere ningún tipo de peligro; antes bien, los consumidores están interesados en bienes que, de ser conocido su potencial de peligro a cabalidad por una persona juiciosa, esta no dejaría de utilizarlos o consumirlos para así evitar un daño a su vida o salud individual ${ }^{65}$. Luego, sobre los fabricantes pesa (únicamente) el deber jurídico de colocar en el mercado productos cuyo potencial de riesgo se haya reducido hasta un nivel tal que una persona juiciosa no dejaría de emplearlos o consumirlos ${ }^{66}$. Un fabricante cumplirá con tal obligación cuando, por ejemplo, coloque en el mercado un producto de limpieza para uso doméstico que satisfaga estándares suficientes de seguridad en relación con los peligros de intoxicación por emanación de gases, y proporcione al consumidor información completa para una utilización segura del producto. Bajo tales condiciones, un consumidor juicioso no dejaría de utilizar el producto de limpieza. Por el contrario, un consumidor sensato no lo emplearía si el bien resultara mortal por la sola inhalación de los gases que de él emanan, o no se le advirtiera acerca de los graves peligros que conlleva su uso; en estos casos, el fabricante habrá infringido sus deberes de reducción de riesgos. En suma, un fabricante cumplirá con su deber de reducción de peligros respecto de un determinado producto cuando limite el riesgo hasta un umbral tal que un consumidor razonable, interesado en la mantención de su vida y salud individual, no dejaría de utilizar el producto, a pesar del conocimiento que tenga de los peligros que puede acarrear su empleo. Luego, todos los riesgos (de carácter residual) de causación de resultados que subsistan pese al cumplimientos de ese deber -riesgos surgidos de la inobservancia de las advertencias del fabricante, peligros provenientes del abuso del producto, etc.- habrán de catalogarse como tolerados.

Finalmente, hay que señalar que el deber de reducción de peligros puede conllevar, dado el caso, que el fabricante renuncie por completo a la

las exigencias de cuidado en el ámbito de la responsabilidad por el producto han de fijarse teniendo en cuenta aquellos riesgos que un consumidor estaría dispuesto a aceptar a través de una ponderación de intereses. En el caso de la colza, cientos de personas que consumieron aceite desnaturalizado resultaron muertas o lesionadas en España durante la primavera de 1981. Los responsables fueron una serie de empresarios dedicados al rubro del aceite, quienes desviaron al consumo humano aceite de colza mezclado con anilina, el que únicamente podía ser empleado con finalidades industriales (lubricante para máquinas). En detalle sobre este caso, entre otros, RodríGuez (1996), pp. 263 y ss.; PARedes (2000), pp. 87 y ss.; PAREDES (2011), pp. 425 y ss.

${ }^{65}$ Destaca el papel de los intereses de los consumidores en la concreción del comportamiento típico CORCOY (2016), p. 497.

${ }^{66}$ Por persona juiciosa debemos entender aquella persona no dispuesta a someter sus bienes jurídicos a riesgos innecesarios. 
comercialización del producto ${ }^{67}$. Esto ocurrirá cuando, por una parte, el fabricante no disponga de ninguna medida que le permita minimizar un riesgo grave del producto y, además, no exista ningún interés por parte de los consumidores en acceder a él. Así ocurrió, precisamente, en el conocido caso de la colza, donde no era posible eliminar la anilina (sustancia venenosa) del aceite de uso industrial, por lo que los empresarios aceiteros estaban obligados a no comercializar en ningún caso el producto ${ }^{68}$.

\subsubsection{Los riesgos del producto que han de ser reducidos}

Habiéndonos referido al umbral hasta el cual han de ser reducidos los riesgos del producto, corresponde ahora abordar la cuestión relativa a qué tipo de peligros son los que el fabricante ha de disminuir o, dado el caso, eliminar. Sobre el particular, hay que recalcar que el fabricante no tiene el deber de disminuir probabilidades de realización de riesgos de muy baja ocurrencia, cuando esa disminución suponga la imposición de cargas que no guarden relación con la magnitud de la posible lesión a bienes jurídicos ${ }^{69}$. Además, no existe ninguna obligación de minimizar aquellos riesgos del bien de consumo que surgen de su uso irracional o socialmente inusual. Únicamente aquellos peligros del producto que resultan de la utilización conforme a su finalidad o de su empleo incorrecto, pero racionalmente previsible o "socialmente habitual", han de ser reducidos. Es evidente que los consumidores están interesados en productos que no representen ningún riesgo en caso de que estos sean empleados de acuerdo con su finalidad; los consumidores esperan del fabricante -precisamente- esa clase de productos ${ }^{70}$. En caso de que no se puedan excluir por completo los peligros que surgen de la utilización según la finalidad del bien, los consumidores esperan que el fabricante les informe de tales riesgos ${ }^{71}$. La exclusión o reducción de aquellos peligros que surgen del empleo conforme a la finalidad del producto es parte de la prestación que el fabricante está obligado a aportar al consumidor, y por la cual este paga ${ }^{72}$. Al fabricante no le puede estar permitido comercializar productos cuya finalidad de empleo él mismo ha fijado a través de publicidad, manuales de instrucciones o de uso, etc., y, simultáneamente, poner en peligro la vida y salud de los consumidores en caso de que estos empleen el

\footnotetext{
67 SChmidt-Salzer (1990), número marginal 4.779.

68 Sts de 23 de abril de 1992, pp. 8827 y ss.

69 SChmidt-Salzer (1990), número marginal 4.844.

70 FRISCH (1988), p. 201.

71 Al respecto, FrISCH (1988), p. 199.

72 FrISCH (1988), p. 201.
} 
producto de acuerdo con su normal destino ${ }^{73}$. Por otra parte, los consumidores también esperan productos que sean seguros en caso de utilización incorrecta, cuando esta pueda calificarse como racionalmente previsible o "socialmente habitual"74. Porque es de común ocurrencia que los consumidores le den al producto un uso que va más allá de su finalidad propia o malinterpreten su uso correcto, empleándolo fuera de su finalidad natural ${ }^{75}$. Así, por ejemplo, los desatornilladores son empleados frecuentemente como cinceles, a pesar de que semejante uso no corresponde a su normal destino. También un consumidor juicioso, que no quiere exponerse a riesgos innecesarios, puede llegar a dar a los desatornilladores semejante uso. Por lo tanto, aparece como justo obligar al fabricante a reducir los riesgos del producto que surjan de su uso incorrecto, cuando este sea racionalmente previsible o "socialmente habitual". En el ejemplo propuesto, los fabricantes de desatornilladores tienen el deber de considerar su utilización incorrecta como cinceles, ya sea empleando en el diseño materiales especialmente resistentes o, al menos, advirtiendo a los consumidores de los riesgos que acarrea ese uso incorrecto ${ }^{76}$.

A diferencia de lo que ocurre con los riesgos que surgen del uso incorrecto, pero racionalmente previsible o "socialmente habitual", el fabricante no está obligado a disminuir aquellos peligros provenientes del empleo incorrecto e irracional del bien. La razón de ello ha de buscarse en los intereses preponderantes de los consumidores. La mayoría de los consumidores no tienen interés en acceder a productos que no representen un riesgo incluso en caso de utilización incorrecta e irracional. Como ya se apuntó, la fabricación y puesta en el mercado de productos semejantes sería en la gran mayoría de los casos extremadamente onerosa -con el consiguiente aumento de precio, que repercutiría negativamente en el desarrollo de la libertad del propio consumidor- o simplemente imposible desde el punto de vista técnico, con lo cual los mismos consumidores se verían privados de bienes a los que quieren acceder. Naturalmente, algunas personas podrían estar interesadas en acceder a productos que permitan un consumo o utilización seguro incluso en caso de empleo incorrecto e irracional, o abusivo ${ }^{77}$. Sin embargo, quienes pretendan esto tienen que recabar la información necesaria y hacer los esfuerzos por conseguir ese tipo de productos, en la medida en que

\footnotetext{
73 Freund (1992), p. 219; Freund (2009), § 6, número marginal 26.

${ }^{74}$ Sobre este punto, Schumann (2007), p. 98.

75 JetTer y KLindt (2003), § 3, número marginal 56; SCHUMANn (2007), p. 97.

${ }^{76}$ El ejemplo es tomado de Gesss y Doll (2005), § 2, número marginal 44.

77 FRISCH (1992), p. 6.
} 
técnica y económicamente sea posible fabricarlos ${ }^{78}$. Considerando los intereses preponderantes de la mayoría de los consumidores, esas personas no pueden esperar que sus intereses sean tenidos en cuenta, a través de una prohibición de la comercialización de productos que no satisfagan sus expectativas, puesto que ello obstaculizaría el ejercicio de la libertad de la mayoría ${ }^{79}$.

Las consideraciones basadas en la falta de interés en la protección de bienes jurídicos explican también por qué la fabricación y distribución de productos que resultan peligrosos en caso de consumo abusivo -por ejemplo, tabaco y bebidas alcohólicas- no están prohibidas y, por consiguiente, no pueden ser desaprobadas, a pesar de que para el fabricante sea previsible que tales productos pueden causar daños a la vida o salud, en el sentido de los arts. $391 \mathrm{~N}^{\circ} 2,399$ y $494 \mathrm{~N}^{\circ} 5$, todos del CP. Lo mismo rige para alimentos con un alto contenido en azúcar o grasas, que representan riesgos en caso de ingesta frecuente (caries, sobrepeso, diabetes, etc. ${ }^{80}$. Los consumidores no están interesados en la desaprobación de la fabricación y comercialización de productos semejantes; muy por el contrario, existe un gran interés en el disfrute de esos bienes de manera autorresponsable $e^{81}$.

\subsubsection{Criterios para concretar el deber de reducción de peligros}

A continuación, corresponde abordar la cuestión relativa a qué comportamientos concretos deben exigirse al fabricante de un nuevo producto, una vez que este ha identificado un determinado riesgo en caso de uso conforme a la finalidad del bien o de uso racionalmente previsible del mismo. Al respecto, conviene abordar una serie de consideraciones y criterios útiles para la concretización de la conducta debida del fabricante.

\subsubsection{Reglas de seguridad de productos y autorizaciones para la comercialización de productos}

Las reglas de seguridad de productos de naturaleza extrapenal -contenidas en leyes y reglamentos- pueden facilitar considerablemente la respuesta a la cuestión relativa a la conducta exigida para la minimización de los peligros

\footnotetext{
78 FRISCH (1992), pp. 6 y 63.

79 FRISCH (1992), p. 6.

80 Acerca de la autorresponsabilidad del consumidor por los daños a la salud causados por alimentos con altos contenidos de azúcar y grasa, véanse las sentencias del Tribunal Superior del Land Mönchengladbach NJW-RR 2002, 896 ss.; del Tribunal Superior del Land Düsseldorf VersR 2003, 912 ss., y del Tribunal del Land Essen NJW 2005, 2713 ss.

81 FrEUND (2009), § 3, número marginal 8.
} 
del bien de consumo. De este modo, reglas de seguridad previstas en la Ley № 19.496 -sobre protección de los derechos de los consumidores-, en el Reglamento sobre seguridad de los juguetes, en el Reglamento sanitario de los alimentos, etc., pueden ayudar a concretar el comportamiento debido. El presupuesto indispensable para la aplicación de dichas reglas consiste en que el riesgo del producto reconocido por el fabricante $-y$ que ha de disminuirse o eliminarse- coincida con aquella constelación fáctica abarcada por la respectiva regla de seguridad extrapenal. La fabricación y colocación en el mercado de productos, observando las correspondientes reglas extrapenales, solo crearán riesgos tolerados por el derecho ${ }^{82}$. Con todo, frecuentemente, las reglamentaciones de seguridad previstas en leyes y reglamentos tienen un rendimiento limitado para concretar los deberes de reducción de peligros. En efecto, hay numerosos riesgos vinculados con el uso de bienes de consumo respecto de los cuales no existen orientaciones para la disminución de peligros, contempladas en normativas extrapenales ${ }^{83}$. De la ausencia de regulación extrapenal no puede deducirse necesariamente que el ordenamiento jurídico haya querido tolerar la respectiva creación de riesgo, puesto que un vacío legal o reglamentario en materia de seguridad de productos muy pocas veces se sustenta en un permiso consciente de creación de peligros ${ }^{84}$. Respecto de ámbitos de riesgo del producto carentes de regulación expresa en leyes o reglamentos, siempre regirá el deber jurídico general consistente en no crear peligros a los cuales consumidores sensatos no se expondrían.

Los permisos estatales para comercializar ciertos productos también pueden precisar los deberes de reducción de peligros del fabricante, especialmente cuando prevén condiciones obligatorias que este ha de cumplir para colocar en el mercado el respectivo bien de consumo ${ }^{85}$. Empero, el rendimiento de las autorizaciones estatales para concretar los deberes del fabricante es limitado, puesto que la introducción en el mercado de la inmensa mayoría de los productos de consumo no está condicionada a la existencia de un permiso previo emanado de un organismo estatal ${ }^{86}$.

Finalmente, los deberes de reducción de riesgos del fabricante pueden concretarse también a través de reglas extrajurídicas (normas técnicas). Existe

\footnotetext{
${ }^{82}$ Confróntese inc. $2^{\circ}$ del art. 47 de la Ley $N^{\circ}$ 19.496, sobre protección de los derechos de los consumidores.

${ }^{83}$ Así lo evidencia Bosch (2002), p. 418.

${ }^{84}$ MAYER (2008), p. 275.

${ }^{85}$ MAYer (2008), p. 333.

${ }^{86}$ Así lo destaca Weiss (2008), pp. 334 y ss.
} 
una cantidad importante de esta clase de reglas, mucho mayor que la de reglas extrapenales; aquellas representan un efectivo apoyo para fijar cuáles son los correspondientes deberes de diseño, fabricación e instrucción del producto. Cuando las reglas extrajurídicas expresan una adecuada ponderación entre los intereses en la mantención de bienes jurídicos y en el ejercicio de la libertad de acción de fabricantes y consumidores, pueden servir para fijar los límites del riesgo permitido ${ }^{87}$. De este modo, el comportamiento del fabricante, que se ajuste a reglas extrajurídicas que reúnan tales características, creará únicamente riesgos tolerados; la actuación que se desvíe de esas reglas generará, por el contrario, peligros desaprobados en el sentido de los delitos de homicidio simple, lesiones menos graves o lesiones leves (al menos, en la mayoría de los casos) ${ }^{88}$.

\subsubsection{Medidas de reducción de peligros para productos similares}

Si en el caso concreto no existen reglas de seguridad del producto extrapenales o extrajurídicas, ni permisos estatales que permitan aclarar cuáles son las obligaciones de reducción de peligros respecto de un "nuevo" producto, entonces el fabricante puede acudir a medidas de seguridad previstas para productos similares, que ya se hayan mostrado eficaces para la minimización de riesgos. Así, por ejemplo, para elaborar una nueva clase de producto de plástico que utilice nanocompuestos, el fabricante podrá tener a la vista las medidas de disminución de peligros aplicables a productos similares donde también se haya empleado nanotecnología. Si las medidas de seguridad contempladas para productos similares son la manifestación de una adecuada ponderación entre los intereses en la mantención de bienes jurídicos y en el ejercicio de la libertad de acción, entonces los riesgos del producto que subsisten pese a la adopción de las mismas constituirán riesgos tolerados ${ }^{89}$. Si el fabricante no adopta esas medidas e introduce el producto en el mercado, entonces creará normalmente un riesgo desaprobado en el sentido de los delitos de homicidio simple, lesiones menos graves o lesiones leves.

\footnotetext{
87 FRISCH (1988), p. 106.

${ }^{88}$ FrISCH (1988), pp. 104 y ss. En algunos casos, aunque el comportamiento del fabricante se haya desviado de lo prescrito en una regla extrajurídica, solo habrá una creación tolerada de riesgos. Así ocurrirá cuando el nivel de seguridad exigido se logre de un modo alternativo al previsto en la regla y cuando la inobservancia de esta haya sido insignificante, no generándose un estado de incertidumbre para la vida o salud del consumidor.

${ }^{89}$ Al fabricante no se le puede exigir legítimamente más que la observancia de aquello que es considerado como una medida de reducción de riesgos adecuada en interés de la conservación de bienes jurídicos.
} 


\subsubsection{El principio de proporcionalidad como criterio para concretar los deberes de reducción de riesgos}

Un criterio decisivo para concretar los deberes de reducción de riesgos del producto lo constituye el principio de proporcionalidad. Efectivamente, cualquier planteamiento relativo a los deberes de reducción de riesgos que pesan sobre el fabricante ha de tener en cuenta que estos deberes afectan normalmente su derecho a desarrollar actividades económicas, su derecho de propiedad, su libertad de trabajo o, al menos, su libertad general de actuación. Además, estos deberes pueden (y esto es frecuentemente inadvertido) afectar la libertad de los propios consumidores ${ }^{90}$. Esto se vuelve especialmente evidente tratándose de la prohibición de comercializar ciertos productos ${ }^{91}$. Pero también un aumento en las exigencias de seguridad de determinados bienes puede coartar la libertad de los consumidores, puesto que medidas semejantes traen normalmente como consecuencia un incremento de los costos de producción y, por consiguiente, de los precios ${ }^{92}$. Como la imposición de deberes de reducción de peligros trae aparejada una afectación de la libertad del fabricante y, dado el caso, del propio consumidor, esa imposición tiene que ser legitimada. Para legitimar los deberes de reducción de peligros han de concurrir todas aquellas exigencias que imperan tratándose de cualquier limitación de derechos fundamentales, en especial ha de satisfacerse el principio de proporcionalidad ${ }^{93}$. Por lo tanto, la imposición de un deber de reducción de peligros solo puede operar cuando este resulte idóneo y necesario para proteger la vida y salud de los consumidores. Además, el deber ha de representar un medio adecuado o razonable para la protección de bienes jurídicos, teniendo en cuenta la importancia de la libertad general de actuación (u otra libertad o derecho de rango constitucional afectado por la imposición del deber), por una parte, y la relevancia de los intereses en la conservación de bienes jurídicos, por otra ${ }^{94}$. Estos criterios fundamentales han de dar respuesta a la pregunta relativa a la concreción de los deberes de reducción de peligros del fabricante ${ }^{95}$.

\footnotetext{
90 WeISS (2008), p. 46.

91 Así, por ejemplo, el inciso segundo del art. $3^{\circ} \mathrm{A}$ de la Ley sobre Control de Armas, $\mathrm{N}^{\circ} 17.798$, de 1972, prohíbe la comercialización de determinados fuegos artificiales y artículos pirotécnicos.

92 WeISS (2008), p. 46.

93 Kremer-Bax (1999), pp. 23 y 65.

94 FRISCH (1988), pp. 74 y ss.

95 El que el principio de proporcionalidad no solamente permita la legitimación, sino también la concreción de deberes de conducta es algo ampliamente aceptado en el derecho civil y penal alemán. Al respecto, Bghst 37, 106, 121 ss.; Bodewig (1999), p. 210; Holtermann (2007), p. 39; Kuhlen (2005),
} 
En primer lugar, los deberes de reducción de riesgos del fabricante tienen que representar un medio idóneo para lograr la protección de la vida y salud del consumidor. Estos deberes constituirán un medio idóneo cuando, por su intermedio, se pueda favorecer la finalidad de protección de tales bienes jurídicos ${ }^{96}$. Las meras prohibiciones de causación de resultados -por ejemplo: "no fabrique medicamentos cuya utilización pueda conducir a daños en la salud de los consumidores"- no son idóneas para alcanzar la protección de bienes jurídicos y, en consecuencia, no son justificables. De esas prohibiciones de causación de resultados el fabricante solo puede inferir qué cursos causales lesivos para bienes jurídicos se deben evitar, pero no cómo debe hacerlo ${ }^{97}$. Por lo demás, casi todos los medicamentos provocan efectos secundarios perjudiciales para la salud, por lo que una prohibición semejante difícilmente podría ser cumplida. Un orden primario en materia de seguridad de productos, que pretenda alcanzar una efectiva protección de la vida y salud de los consumidores, presupone exigencias de comportamiento concretas, que sean realmente idóneas desde una perspectiva ex ante para reducir o excluir el riesgo (por ejemplo: "no emplee talidomida en medicamentos destinados a mujeres embarazadas", "informe el efecto secundario anticoagulante de un medicamento para evitar daños a pacientes hemofílicos", etc.).

En segundo lugar, los deberes de reducción de riesgos del producto han de ser un medio necesario para proteger la vida y salud de los consumidores. La imposición de tales deberes será necesaria cuando la conservación de esos bienes jurídicos no se puede alcanzar de igual forma a través de un mecanismo menos gravoso para los derechos fundamentales del productor ${ }^{98}$. El examen de necesidad de un determinado deber de reducción de peligros presupone que no exista un medio menos lesivo para la libertad o derechos del fabricante, que permita lograr de manera igualmente eficaz la finalidad perseguida de protección de la vida y salud de los consumidores ${ }^{99}$. En el ámbito del derecho alemán de la seguridad del producto, el mandato de necesidad se ha mostrado especialmente efectivo para limitar la potestad del legislador ${ }^{100}$. Así, por ejemplo, el Bundesverfassungsgericht ha declarado inconstitucional una prohibición abso-

pp. 362 y ss.; RETTENBECK (1994), p. 66. En detalle sobre la aplicación del principio de proporcionalidad para la concreción de los deberes de conducta del fabricante de alimentos, DomeIER (1999), pp. 107 y ss.

96 BVerfGE 63, 88, 115; 67, 157, 175; 96, 10, 23; 103, 293, 307.

97 Así lo evidencia Reus (2010), p. 83.

${ }_{98}$ BVerfGE 38, 281, 302; 49, 24, 58; 113, 29, 53 y ss.

99 BVerfGE 113, 167, 259.

100 Así lo destaca Hufen (2017), § 9, número marginal 22. 
luta de comercialización de golosinas, puesto que la finalidad de protección del consumidor se puede alcanzar igualmente a través de deberes de advertencia ${ }^{101}$. Como veremos en infra 3.2.4, el mandato de necesidad juega un importante rol para la determinación de los deberes de diseño e instrucción del productor.

En tercer lugar, los deberes de limitación de riesgos han de ser adecuados para la protección de la vida y salud de los consumidores. El criterio de adecuación exige que los intereses de fabricantes y consumidores sean puestos en una relación recíprocamente razonable. En el ámbito de la responsabilidad por el producto, un deber de reducción de peligros podrá calificarse como adecuado cuando la limitación de la libertad de fabricantes y consumidores que conlleva no "pese" más que la necesidad de protección de la vida y salud existente en el caso concreto ${ }^{102}$. Por ello, la adecuación de un deber de reducción de peligros solo concurrirá cuando -ponderando todos los intereses en juego- quede un "saldo" en favor de la imposición del deber ${ }^{103}$. Solo así la norma de conducta será expresión de una valoración jurídica correcta y, en consecuencia, podrá ser aceptada por los fabricantes, lo que es indispensable para su efectivo acatamiento ${ }^{104}$. La adecuación de un deber de conducta en materia de seguridad de productos presupone siempre una ponderación jurídica del conjunto de intereses en juego, en especial de los intereses en la mantención de bienes jurídicos y en el ejercicio de la libertad de los consumidores, y de los intereses en el desarrollo de la libertad de los fabricantes.

Ahora bien, la afirmación de que es necesario ponderar todos los intereses en juego, para así comprobar la adecuación de un deber de limitación de peligros del producto, no está en condiciones por sí misma de fijar qué es lo que el derecho en un caso concreto le puede exigir legítimamente al fabricante. Para ello, es necesario disponer de un criterio o pauta que permita guiar la ponderación de los de intereses en juego. En la jurisprudencia y doctrina alemanas se destaca frecuentemente que el criterio "mientras mayor el riesgo, más intenso el deber" permitiría dirigir el proceso de ponderación; así, se afirma que mientras más grave sea el peligro vinculado con el uso de un producto, y mientras más probable sea que ese peligro se concrete en un resultado lesivo, más estrictas deben ser las exigencias de seguridad que se impongan al fabricante ${ }^{105}$. Frente

101 BVerfGE 53, 135, 145 y ss.

102 Domeler (1999), pp. 99 y 136.

103 Freund (2009), § 1, número marginal 20.

104 Freund (1991), p. 396; FreUnd (2009), § 1, número marginal 20.

105 Sentencia del Tribunal del Land Múnich II, reproducida en SChmidt-Salzer (1982), p. 330; EICHINGer (1997), p. 221; MAYER (2008), pp. 267 y 279. 
a afectaciones a bienes jurídicos leves o de acaecimiento poco probable, solo se pueden exigir cargas menores a los productores ${ }^{106}$. En definitiva, el tipo y dimensión de las medidas de seguridad de un bien de consumo tienen que guardar relación con la magnitud del peligro que su uso conlleva ${ }^{107}$. En contra de la fórmula "mientras mayor el riesgo, más intenso el deber" se puede plantear una importante objeción: es un criterio extremadamente vago y no ofrece ningún parámetro que permita esclarecer a partir de qué medida o grado de riesgo se gatillan qué tipo de exigencias adicionales de seguridad. Su aplicación abre las puertas al más puro decisionismo judicial. Por lo demás, en muchas ocasiones será imposible establecer con exactitud la medida o grado de riesgo de determinados productos, con lo cual tampoco se podrá saber qué mecanismos de disminución de peligros son los requeridos; al respecto, piénsese en nuevas clases de medicamentos, cuyo potencial de daño es -respecto de ciertos ámbitos específicos- frecuentemente incierto ${ }^{108}$. Otra crítica en contra de la fórmula "mientras mayor el riesgo, más intenso el deber", consiste en que esta sobrevalora la importancia de la medida o grado de peligro del producto como criterio de adecuación de los deberes del fabricante, y deja sin considerar los intereses de los consumidores en el acceso al producto. Si se fuera consecuente con esta fórmula, la fabricación y puesta en el mercado de bienes de consumo con un potencial de daño muy elevado -como, por ejemplo, tabaco de mascar, sustancias altamente inflamables o armas blancas- deberían, incluso, prohibirse. Sin embargo, una medida semejante representaría una limitación inexigible de la libertad del fabricante y afectaría, además, de manera sustancial los intereses de los propios consumidores. La fórmula "mientras mayor el riesgo, más intenso el deber" desconoce que la seguridad no es el único valor que tiene que ser considerado para fijar la adecuación de los deberes de seguridad en materia de bienes de consumo.

Un criterio que sí permite orientar de manera racional y justa el proceso de ponderación, en el contexto de la configuración los deberes jurídicos del fabricante, lo constituye el principio de capacidad de aceptación recíproca de la solución que resulte de tal proceso. Para ello, la ponderación necesaria para legitimar los deberes del productor ha de orientarse hacia un resultado que pueda ser aprobado por todos los individuos, con independencia de la posición

106 BoDewIG (1999), p. 219.

107 Foerste (2012a), número marginal 18; SCHMidT-Salzer (1988), número marginal 1.332.

108 Weiss (2008), p. 54. 
que ocupen en la relación jurídica fijada por el respectivo deber ${ }^{109}$. En otras palabras, el deber jurídico tiene que ser razonable, recíprocamente, para todos los involucrados.

De conformidad con el principio indicado, un deber jurídico de reducción de los peligros del producto representará una adecuada ponderación de intereses en la mantención de bienes jurídicos y en el ejercicio de la libertad, cuando una persona razonable, que no conociera su posición en la sociedad como consumidor o como fabricante, se mostraría de acuerdo con la imposición del deber. Probablemente, una persona sensata se mostraría conforme con la imposición del deber de reducción de peligros cuando este reuniera dos condiciones copulativas. Por una parte, cuando a través del cumplimiento del deber, el riesgo del producto disminuyera de tal modo que una persona interesada en la conservación de sus bienes jurídicos no evitara el uso del producto, si conociera sus peligros tan bien como el fabricante ${ }^{110}$. Por otra parte, cuando la observancia del deber de reducción de peligros no afectara el uso que se puede dar al producto, o no aumentara de manera significativa su costo de producción (y, con ello, su precio), privando al sujeto de bienes de consumo a los que desea acceder ${ }^{111}$. Ciertamente, los individuos no están interesados en medidas de reducción de peligros que priven al producto de la utilidad que le es propia. Por eso, un fabricante no puede estar obligado - a través de diseños alternativos más seguros- a eliminar aquellos riesgos que son consustanciales a la función del producto; por ejemplo, el peligro de causación de lesiones proveniente del uso de cuchillos y tijeras ${ }^{112}$. El fabricante tampoco tiene la obligación de eliminar aquellos peligros del producto que, si bien no son consustanciales a su función, son asumidos como valiosos por los consumidores, teniendo en cuenta

\footnotetext{
109 Acerca de la capacidad de aceptación recíproca como punto de partida de una ponderación, véase SIECKMANN (1995), p. 181.

110 Del mismo modo, un fabricante que utilizara los productos elaborados por él se mostraría de acuerdo con este presupuesto de adecuación de los deberes de reducción de riesgos. Sobre la relevancia de este tipo de consideraciones, véase el apartado 3.2.1, "Cuestiones preliminares".

111 Consideraciones similares juegan un importante rol tratándose del criterio del derecho civil de la "alternativa de seguridad del mismo valor", que se emplea para examinar la legitimación de los deberes de diseño. Conforme a este criterio, un deber de diseño es expresión de una adecuada ponderación de intereses en la conservación de bienes jurídicos y en el ejercicio de la libertad, cuando el fabricante no pueda configurar el producto de un modo más seguro -a través de un diseño alternativo- sin afectar su utilidad y sin un aumento inexigible de costos. Sobre el criterio de la "alternativa de seguridad del mismo valor", BGH NJW 1990, 906, 907; HörL (1999), pp. 118 y ss.; KÖtZ (1991), p. 115; WAGNer y WITTE (2005), pp. 903 y ss.

112 HÖRL (1999), p. 126.
} 
otras cualidades deseadas ${ }^{113}$. Además, el derecho no puede exigir al fabricante seguridad absoluta a cambio de costos económicos inexigibles, que impidan la venta del bien de consumo ${ }^{114}$. Esto no solo afectaría de manera desproporcionada la libertad económica del fabricante ${ }^{115}$, sino, además, la libertad de actuación de los propios consumidores, privándolos de productos que desean adquirir. Por eso, un deber de reducción de peligros solo será expresión de una adecuada ponderación de intereses en la mantención de bienes jurídicos y en el ejercicio de la libertad cuando no dé lugar a una imposición de costos insoportables ${ }^{116}$, los que habrán de apreciarse cuando el producto no pueda ser ofrecido a terceros desde un punto de vista económicamente sostenible ${ }^{117}$.

Teniendo en consideración las reflexiones recién expuestas, es posible responder la pregunta relativa a si una regla de seguridad extrajurídica, o una medida de reducción de riesgos que rige para productos similares, constituye en el caso concreto una ponderación adecuada de intereses y, en consecuencia, puede servir para la concreción de los deberes de limitación de peligros que el fabricante tiene que acatar. Cuando semejante regla o medida no incremente de manera desmedida los costos de producción, ni tampoco afecte la utilidad del bien de consumo, además de disminuir el riesgo hasta un punto tal que un consumidor juicioso no dejaría de emplear el bien, entonces aquella representará un medio adecuado para la protección de la vida y salud de los consumidores. Estos mismos criterios pueden servir de guía fundamental para la concreción de los deberes de reducción de peligros del fabricante, cuando en el caso concreto no existan reglas extrajurídicas, ni tampoco medidas de limitación de riesgos para productos similares, que resulten aplicables.

\subsubsection{Concreción de los deberes de diseño y de instrucción a través del principio de proporcionalidad}

A continuación, se intentará ejemplificar de qué manera el principio de proporcionalidad, cuyo alcance en el campo de la responsabilidad del fabricante

\footnotetext{
113 HÖRL (1999), p. 127. Ejemplo: los fabricantes de cigarrillos no deberían estar obligados a elaborar unidades que contengan una cantidad muy reducida de nicotina o alquitrán, puesto que con ello el producto perdería ciertas cualidades que ocasionan la sensación de placer al fumar. Así lo destacan WAGNeR Y WITTE (2005), p. 904.

114 Foerste (2012b), número marginal 179, con abundantes citas.

115 Schumann (2007), p. 94.

116 HÖRL (1999), p. 132.

117 En este sentido, Grosse Vorholt (1997), p. 88.
} 
ha sido recién descrito, permite concretar los deberes de reducción de peligros; para ello, nos referiremos, en particular, a los deberes de diseño y de instrucción.

\subsubsection{Los deberes de diseño}

Como ya se indicó en supra 2, el cumplimiento del deber jurídico consistente en colocar en el mercado productos que, en caso de utilización conforme a su finalidad o razonablemente previsible, no representen ningún peligro para los bienes jurídicos de los consumidores, presupone que el fabricante evite los defectos de diseño. Este tipo de defectos surgen cuando la concepción o diseño original del bien de consumo es errado, y pueden estar causados por el empleo de materiales peligrosos, la realización de cálculos equivocados o una evaluación incorrecta de las cualidades de seguridad del prototipo del bien ${ }^{118}$. Para prevenir los defectos de diseño, el fabricante tiene que idear el producto diligentemente, de modo tal que asegure la ausencia de peligrosidad del bien, en caso de utilización de este conforme a su finalidad o racionalmente previsible ${ }^{119}$.

Conviene plantear la pregunta de si los deberes de diseño representan un mecanismo necesario para la protección de los bienes jurídicos de los consumidores, en aquellos casos en que existen medidas de instrucción que también permiten la disminución de peligros. Una simple advertencia al consumidor que Ilame su atención sobre el riesgo representa, normalmente, una medida más barata que un diseño alternativo del producto y, en consecuencia, su implementación constituye, comparativamente, un medio menos gravoso para el ejercicio de la libertad del fabricante ${ }^{120}$. De acuerdo con el mandato de necesidad, el ordenamiento primario no podría exigir al fabricante el cumplimiento de un deber de diseño, si la observancia de un deber de instrucción es suficiente para la conservación de bienes jurídicos ${ }^{121}$. Sin embargo, para que la imposición de un deber de diseño sea ilegítima por falta de necesidad, han de reunirse, en el caso concreto, dos requisitos copulativos. En primer lugar, la advertencia del riesgo al consumidor tiene que ser igual de idónea para proteger su vida y salud que la respectiva medida de diseño; además, la obligación de advertencia tiene que gravar el ejercicio de la libertad del fabricante de manera -efectivamente- menos severa que la correspondiente medida de diseño. Respecto a la primera de las condiciones mencionadas, la doctrina señala que en la mayoría de los casos las

\footnotetext{
118 Foerste (2012b), número marginal 71; HaGer (2009), número marginal F 12; WaGNer (2017), número marginal 818 .

119 BrügGemeier (2006), p. 410.

120 Así lo destaca Hörl (1999), p. 111; WaGner (2017), número marginal 821.

121 MÖllers (1996), p. 290.
} 
advertencias e instrucciones son menos efectivas que las medidas de diseño ${ }^{122}$. A menudo, los consumidores malinterpretan las advertencias del producto o, simplemente, no les prestan atención ${ }^{123}$. Además, hay consumidores potenciales del producto, tales como niños de corta edad o ciudadanos extranjeros, que no dominan la lengua del lugar en que residen y que, por consiguiente, no están en condiciones de entender las advertencias ${ }^{124}$. Finalmente, hay informaciones relativas a los riesgos del producto que no permiten -de ninguna forma- evitar el desencadenamiento de cursos causales lesivos en el sentido de los delitos previstos en los arts. 391 № 2, 399 o 494 № 5 del CP (a título doloso o culposo, dado el caso) ${ }^{125}$. A modo de ejemplo: el desprendimiento de la superficie de los neumáticos de un automóvil, a causa de graves errores de diseño, no puede ser evitada por los automovilistas, ni siquiera conduciendo sus vehículos de manera cuidadosa. En este caso, la advertencia relativa a los peligros del uso de tales neumáticos no es, en principio, idónea para la conservación de bienes jurídicos. La constatación de que la incorporación al producto de advertencias usualmente representa un medio menos eficaz para el control de peligros -en comparación con las medidas de diseño- explica por qué en la responsabilidad civil del fabricante los deberes de diseño prevalecen sobre los deberes de instrucción ${ }^{126}$. Efectivamente, en el campo del derecho civil se señala que los deberes de instrucción solo entran en consideración cuando los riesgos del producto no pueden ser evitados a través de medidas de diseño, o cuando tales medidas resultan inexigibles para el fabricante y, pese a ello, la comercialización del producto ha de admitirse por existir un interés en tal sentido por parte de los consumidores ${ }^{127}$. Es decir, en el ámbito del derecho civil se plantea que los peligros del producto solo deben ser minimizados a través de advertencias cuando técnicamente no sea posible la reducción de peligros a través de medidas de diseño, o cuando esto sí sea factible, pero la implementación de

\footnotetext{
122 Hörl (1999), p. 111; MÖLlers (1996), p. 250.

123 Rettenbeck (1994), p. 71.

124 HÖRL (1999), p. 88.

125 MÖllers (1996), p. 250.

126 FOeRSTE (2012b), número marginal 127; HAGER (1990), p. 403; HÖRL (1999), p. 89; MAYER (2008), p. 283; WAGNER (2017), número marginal 821; WILRICH (2004), § 4, número marginal 56. Ya en el "caso del adaptador eléctrico", el Tribunal Supremo Federal alemán indicó que el fabricante no puede eludir sus obligaciones de diseño a través de meras advertencias a los consumidores. En este caso, el fabricante había omitido incorporar al dispositivo una conexión a tierra, agregando simplemente un aviso del siguiente tenor: "Cuidado, sin puesta a tierra"; el fabricante fue condenado por homicidio culposo [sentencia del 17 de febrero de 1959, reproducida en SCHMIDT-SAlzer (1982), pp. 170 y ss.].

127 BGH NJw 2009, 2952, 2954; BrügGemeler (2006), p. 413.
} 
tales medidas implique costos tan elevados, que no sea exigible al fabricante su adopción y, a pesar de ello, los consumidores estén interesados en acceder al producto (acompañado de las respectivas advertencias). En lo que respecta al segundo presupuesto del criterio de la necesidad, hay que señalar que el cumplimiento de los deberes de instrucción no siempre podrá ser considerado como el medio menos gravoso para el fabricante. Ello ocurre porque cuando se exige al fabricante que incorpore al producto advertencias explícitas sobre los peligros vinculados con su uso, las posibilidades de venta del bien pueden verse drásticamente limitadas ${ }^{128}$. Además, el cumplimiento de deberes de instrucción puede traer aparejados altos costos económicos, cuando los peligros potenciales del producto, que han de ser comunicados, tienen que ser previamente investigados por el fabricante, tal como ocurre con los efectos secundarios de los medicamentos ${ }^{129}$. En definitiva, en comparación con los deberes de diseño, las obligaciones de instrucción no siempre representan un medio menos gravoso para alcanzar una protección idónea de la vida y salud de los consumidores. En algunos casos, los deberes de diseño pueden representar un medio necesario para la conservación de bienes jurídicos.

\subsubsection{Los deberes de instrucción}

Si en el caso concreto, y de acuerdo con el estado de la técnica, no se puede excluir un peligro para los consumidores en caso de uso del producto conforme a su finalidad o de un modo racionalmente previsible; o la implementación de medidas de diseño para la evitación de riesgos resultan inexigibles para el fabricante y, a pesar de ello, existe un interés de los consumidores en la adquisición del producto, entonces el fabricante está obligado a informar de sus riesgos ${ }^{130}$. Este deber de instrucción del fabricante, contemplado en el inc. $1^{\circ}$ del art. 45 de la Ley $N^{\circ} 19.496$, halla su origen en la circunstancia de que, en comparación con el consumidor, aquel cuenta con un conocimiento superior respecto del peligro del producto. Imponer al fabricante un deber de instrucción aparece enteramente justo y razonable, puesto que él "está más cerca" que nadie de la correspondiente información relativa al peligro, la puede proporcionar a los demás sin mayor dificultad, limitando así de manera eficaz los respectivos riesgos del bien ${ }^{131}$. Para los consumidores es inviable la mayoría de las veces procurar-

\footnotetext{
128 HÖRL (1999), pp. 111 y ss.

129 MÖlleRs (1996), p. 304.

130 BGH NJw 2009, 2952, 2954; Brüggemeier (2006), p. 413; Foerste (2012 b), número marginal 217; Meyer (1992), p. 112; SChmidt-Salzer (1990), número marginal 4.1114.

131 MÖllers (1996), p. 251.
} 
se la información relativa al riesgo del producto $^{132}$; conseguir tal información solo sería posible luego de un esfuerzo (en tiempo, recursos económicos, etc.) totalmente inexigible ${ }^{133}$.

Ahora bien, el fabricante únicamente ha de advertir aquellos peligros que sean cognoscibles de acuerdo con el estado de la técnica. Si, conforme a este, el productor no se encuentra en condiciones de reconocer los peligros vinculados con la utilización del producto, entonces no es posible obligarlo a informar el respectivo riesgo, con independencia de que este exista ${ }^{134}$. Si, en cambio, el productor logra-apoyándose en el estado de la técnica- reconocer los peligros del bien, entonces surgen dos importantes cuestiones. Primera: ¿hace falta en el caso concreto la respectiva advertencia?, y segunda: si la respuesta es afirmativa, ¿cómo se concreta su contenido, forma y extensión? Para abordar ambas cuestiones, deben considerarse nuevamente las exigencias de idoneidad y necesidad.

Efectivamente, los deberes de instrucción solo son necesarios y, en consecuencia, legítimos, en la medida en que los peligros a los cuales se refieren no formen parte del conocimiento basado en la experiencia general del consumidor ${ }^{135}$; esto es, aquel saber que un consumidor promedio -perteneciente al grupo al que está destinado el producto- ha adquirido a través de su experiencia de vida, su formación en la escuela o a través de la enseñanza del grupo familiar ${ }^{136}$. Dentro de este tipo de conocimiento podemos mencionar, por ejemplo, el que los alimentos con un alto contenido en azúcar son nocivos para la salud ${ }^{137}$ o el que beber importantes dosis de alcohol de manera habitual puede provocar graves daños al organismo. Tratándose de conocimientos semejantes, no es necesaria una advertencia, puesto que esta no entrega al consumidor una información distinta a la que ya posee por sí mismo ${ }^{138}$. Por ello, la imposición de un deber de instrucción respecto de tales

\footnotetext{
132 HÖRL (1999), p. 66.

133 MÖlleRs (1996), p. 251.

134 Los peligros del producto que ni siquiera un fabricante diligente es capaz de reconocer, aplicando todo el cuidado exigible, constituyen precisamente los denominados "riesgos de desarrollo". Al respecto, véase el apartado 3.1.1, "Consideraciones generales acerca del criterio de la reconocibilidad".

135 BGH NJw 1975, 1827, 1829; 1986, 1863, 1864; 1999, 2815, 2816; Von Bar (1998), p. 32; Foerste (2012b), número marginal 246; HaGeR (2009), número marginal F 14.

136 Holst (2006), p. 59.

137 Olg Düsseldorf VersR 2003, 912, 915.

138 HÖRL (1999), p. 141. La obligación de destacar las características nutricionales de los alimentos, incorporando en los envases respectivos un símbolo con el texto "alto en grasas saturadas", "alto en sodio", etc., sí es necesaria, puesto que permite informar al consumidor que el producto alimenticio
} 
conocimientos infringiría el principio de proporcionalidad ${ }^{139}$. Los deberes de instrucción tampoco resultan procedentes cuando el respectivo producto está dirigido a personas que, por la labor que realizan, tienen conocimientos detallados del peligro -por ejemplo, personal técnico o especializado en determinadas áreas- ${ }^{140}$. Por eso, el Tribunal Supremo Federal alemán declaró en una antigua sentencia que el fabricante de grúas para ventanas no tiene ninguna obligación de advertir de los riesgos del uso de estos aparatos, puesto que son perfectamente conocidos por los respectivos círculos de usuarios ${ }^{141}$. Con todo, los deberes de instrucción se vuelven innecesarios únicamente cuando todas las dimensiones del peligro son evidentes para el especialista ${ }^{142}$; algo distinto rige tratándose de riesgos específicos del producto que para el personal experto no son previsibles ${ }^{143}$. Así, por ejemplo, a pesar de que el peligro de la aplicación de anestésicos por vía intraarterial, en lugar de por vía intravenosa, es generalmente conocido por los médicos, resulta necesaria una advertencia expresa en caso de que un suministro por la vía equivocada provoque graves reacciones vasculares, que puedan conducir, incluso, a la amputación de una extremidad ${ }^{144}$.

Por otra parte, el contenido, la forma y la extensión de las advertencias de los productos han de ser concretados a través de la exigencia de idoneidad, esto es, las advertencias con que se acompañen los bienes de consumo tienen que ser apropiadas para alcanzar su finalidad, que no es otra que la de dotar a los consumidores de la capacidad de identificar y evitar los riesgos del producto. En consecuencia, las advertencias del producto han de hacerse en idioma español (inc. $1^{\circ}$ del art. 45 de la Ley $N^{\circ} 19.496$ ) y presentarse de tal modo que los consumidores puedan percibirlas, comprender su contenido y acatarlas ${ }^{145}$; para ello, deben ser claras y entendibles por la generalidad de

\footnotetext{
tiene determinadas características que en muy numerosas ocasiones no son fácilmente reconocibles (véase art. 120 bis del Reglamento sanitario de los alimentos).

139 En su variante de necesidad, el principio de proporcionalidad no solo se quebranta cuando se elige un medio más gravoso que otro igualmente eficaz para alcanzar un fin legítimo, sino también cuando para lograr el fin no es necesario gravar el ejercicio de ningún derecho constitucional.

140 BGHz 116, 60, 65 s.; BGH NJw 1999, 2815, 2816; HAGER (2009), número marginal F 14; HOLST (2006), p. 67; MeYer (1992), p. 127.

141 BGH Versr 1959, 523, 524 y ss.

142 Meyer (1992), p. 127.

143 Holst (2006), p. 67.

144 BGH NJw 1972, 2217, 2220 y ss.

145 Holst (2006), p. 102.
} 
la población ${ }^{146}$. La claridad de las instrucciones del producto presupone una adecuada estructuración de la información, que permita que aquellos datos que se buscan sean rápidamente encontrados, y que se destaque aquello más importante por sobre lo menos relevante ${ }^{147}$. Que la información sea entendible por la generalidad significa que las advertencias han de expresarse en un lenguaje comprensible para el círculo de consumidores que entrará en contacto con el producto ${ }^{148}$. En caso necesario, el fabricante debe intentar comunicar los riesgos del producto por medios distintos del lenguaje escrito, por ejemplo, a través de símbolos o pictogramas; estos pueden ser especialmente necesarios tratándose de consumidores que solo hablan una lengua extranjera ${ }^{149}$. Por otra parte, exigir advertencias detalladas y llamativas respecto de todos y cada uno de los peligros de un producto -con independencia de la magnitud de los respectivos riesgos-, puede conducir a una desensibilización de los consumidores o a la creación de miedos exagerados en estos ${ }^{150}$. Por eso, el fabricante debe priorizar la comunicación de aquellos riesgos del producto más graves y, dado el caso, excluir de las advertencias aquellos peligros poco significativos ${ }^{151}$. También parece ser conveniente no llamar la atención respecto de aquellos riesgos que pueden surgir del abuso del producto (la utilización de una pintura industrial como narcótico, por ejemplo), puesto que cualquier información en tal sentido puede convertirse en el estímulo para el mal uso del bien de consumo y ocasionar más daños que beneficios ${ }^{152}$.

\section{Productos que ya están en el mercado y que el fabricante quiere seguir elaborando y distribuyendo}

Luego de haber explicado en detalle la prohibición de colocar en el mercado productos que sean peligrosos en caso de utilización conforme a su finalidad o racionalmente previsible, que corresponden a "nuevos desarrollos", toca analizar a continuación la cuestión de cómo se concreta dicha prohibición cuando ella se refiere a productos que ya están en el mercado, y que el fabricante pretende seguir elaborando y distribuyendo.

146 BGH NJw 1987, 1009, 1012; BGHz 106, 273, 281; Borer (1986), p. 53; Corral (2013), p. 925.

147 BGH NJw 1995, 1286, 1287; MeYer (1992), p. 141; en el derecho español, Salvador y Ramos (2008), p. 195.

148 MeYer (1992), p. 141.

149 BGH NJw 1987, 372, 373; Holst (2006), pp. 94 y 102; MeYer (1992), p. 142.

150 Así se destaca en Bverfa NJw 1997, 249, 250; Bosch (2002), p. 490.

151 Holst (2006), p. 102.

152 BGH NJw 1981, 2514, 2516; Olg Karlsruhe NJW-RR 2001, 1174; BodewIG (1999), p. 252. 


\subsection{Papel decisivo de las reglas de seguridad de productos o medidas de gestión de riesgos que ya han sido observadas}

En la medida en que no hayan Ilegado a la empresa fabricante noticias de daños ocasionados por el producto en caso de haberse utilizado este de acuerdo con su finalidad, o de un modo incorrecto, pero racionalmente previsible, y siempre que la vigilancia activa ${ }^{153}$ del producto no haya permitido identificar algún defecto en el mismo, el fabricante ha de seguir cumpliendo aquellas reglas de seguridad extrapenales o extrajurídicas, o aquellas medidas de reducción de peligros, que ya había observado anteriormente. Cuando el cumplimiento de determinados deberes de conducta del fabricante se ha mostrado, hasta el momento, como efectivo para la conservación de la vida y salud de los consumidores, no hay ninguna razón para que el derecho exija algo distinto que la observancia de esos deberes, en caso de que se pretenda seguir fabricando y distribuyendo el respectivo producto. La circunstancia de que los correspondientes deberes de conducta hayan sido acatados por el fabricante, y de que el producto no haya ocasionado, hasta el momento, ningún daño (al menos, conocido) a los usuarios, es una clara muestra de la idoneidad, necesidad y adecuación de esos deberes para la protección de la vida y salud ${ }^{154}$. Si las reglas de seguridad de productos o determinadas medidas han sido observadas, entonces ello será muestra de que, muy probablemente, no existirá un medio menos gravoso e igualmente eficaz para la protección de bienes jurídicos y de que tales reglas o medidas no obligan al fabricante a nada que sea inexigible. Y si no han Ilegado a conocimiento del fabricante noticias de daños ocasionados por el uso del producto, o la vigilancia activa de este no ha permitido identificar defectos, entonces ello será muestra de que las reglas de seguridad de productos extrapenales o extrajurídicas, o determinadas medidas de gestión de riesgos, representan un programa de reducción de peligros idóneo para la protección de bienes jurídicos.

\footnotetext{
153 Por "vigilancia activa del producto" debemos entender aquel comportamiento del fabricante consistente en generar y valorar toda aquella información que permita descubrir riesgos del producto no reconocibles al momento de su colocación en el mercado (riesgos de desarrollo). La vigilancia activa puede concretarse, por ejemplo, en un seguimiento de los reclamos en que se hayan visto involucradas empresas que comercializan productos similares, en asistir a seminarios y congresos en que se expongan nuevos descubrimientos sobre los peligros de los productos que se fabrican en la respectiva rama, en suscribirse a literatura técnica que permita tomar conocimiento de estos peligros, etc. Sobre la vigilancia de productos, detalladamente, Foerste (2012b), números marginales 372 y ss.

154 En lo que sigue, FrISCH (1988), p. 106; FrISCH (1996b), p. 104.
} 


\subsection{Descubrimiento de una nueva forma de diseño o fabricación}

Si, después de la colocación en el mercado del producto, se descubre una nueva forma de diseño o fabricación, que resulta ser más barata y que no disminuye el nivel de seguridad del producto (o incluso lo mejora), pareciera evidente que el fabricante puede aplicarla. En tal caso, no estaría justificado exigir al fabricante que siguiera observando las reglas de seguridad correspondientes a la "forma antigua" de diseño o fabricación. Una exigencia semejante atentaría en contra del mandato de necesidad, puesto que el nuevo método representa un medio que permite de igual (o incluso mejor) forma la protección de bienes jurídicos, con un costo menor para el fabricante. Por lo demás, los consumidores no tendrán ningún interés en que el fabricante siga vinculado al método tradicional de diseño o fabricación, puesto que la nueva forma de proceder, menos costosa para el fabricante, redundará - muy probablemente- de un modo favorable en los precios de venta.

Más problemática es la pregunta relativa a qué deberes jurídicos tiene que cumplir el fabricante cuando, después de la colocación en el mercado del producto, se descubre una nueva forma de diseño o fabricación, que mejora el nivel de seguridad del bien de consumo, pero también sus costos de elaboración y, en consecuencia, su precio. En este tipo de casos, ipuede el fabricante seguir elaborando el bien de acuerdo con el método tradicional de diseño o fabricación, que es más barato, pero también más inseguro, o está obligado a elaborar el bien exclusivamente de acuerdo con el nuevo método? Al respecto se ha indicado que el fabricante puede seguir produciendo el bien de consumo de acuerdo con el método tradicional, siempre y cuando informe al consumidor los peligros que conlleva el uso del bien elaborado de conformidad a este método $^{155}$. De esta forma, el consumidor podría decidir si el bien representa para él un riesgo que está o no dispuesto a asumir. Si el consumidor considera que se trata de un peligro no aceptable, entonces puede renunciar a la compra del bien, descartando los daños que su uso pueda traer consigo ${ }^{156}$. La exoneración de responsabilidad del fabricante a través de la entrega de información al consumidor es -en principio- admisible ${ }^{157}$. Y es que, en el marco del ejercicio de la libertad general de actuación del consumidor, este no solo puede decidir qué productos de los ofrecidos en el mercado adquiere, sino también qué

155 HOYER (2009), p. 879.

156 Así lo destaca Grosse Vorholt (1997), p. 110.

157 Grosse Vorholt (1997), p. 109; crítico respecto de la posibilidad de que el fabricante se libere de responsabilidad a través de advertencias al consumidor, BosCH (2002), pp. 484 y ss. 
riesgos está dispuesto a asumir y qué medidas va a adoptar para enfrentarlos ${ }^{158}$. Por eso, evitar aquellos riesgos del producto que provienen de ciertos métodos de diseño o fabricación, que se han advertido claramente, se sitúa dentro del ámbito de responsabilidad del propio consumidor.

\section{Conclusión}

A modo de conclusión, podemos señalar lo siguiente: la responsabilidad penal del fabricante por los delitos de homicidio simple, lesiones menos graves o lesiones leves presupone, en muchos casos, la infracción de la prohibición de colocar en el mercado productos que sean peligrosos en caso de empleo conforme a su finalidad o racionalmente previsible. Un fabricante cumple tal prohibición cuando sus productos están libres de defectos de diseño, de fabricación y de instrucción. Tratándose de bienes de consumo que corresponden a "nuevos desarrollos", la evitación de esos defectos presupone la observancia de los deberes de reconocimiento y de disminución de riesgos. Para estar en condiciones de evitar afectaciones a los bienes jurídicos de los consumidores, el fabricante ha de saber exactamente qué riesgos puede ocasionar el uso del producto; la cognoscibilidad del peligro es el presupuesto necesario para su limitación. Por otra parte, para la concreción del deber de disminución de riesgos del producto es indispensable considerar cuáles son los intereses de los consumidores. Ellos están interesados en productos que, de ser conocido su potencial de riesgo por una persona juiciosa, esta no dejaría de utilizarlos para así evitar un daño en sus bienes jurídicos; además, el interés de aquellos no se dirige a la adquisición de bienes que sean seguros incluso en caso de empleo incorrecto e irracional. Los principios de idoneidad, necesidad y adecuación también permiten dotar de contornos específicos al deber de disminución de riesgos del producto. Respecto de los productos que ya están en el mercado, y que se quieren seguir elaborando y distribuyendo, el fabricante puede limitarse a cumplir aquellas reglas de seguridad extrapenales o extrajurídicas, o aquellas medidas de reducción de peligros, que ya ha observado con anterioridad, en la medida en que no hayan llegado a la empresa noticias de daños ocasionados por los bienes de consumo ya distribuidos. Finalmente, si después de la colocación en el mercado de un producto se descubre una nueva forma de diseño o fabricación, que resulta ser más barata y que no disminuye el nivel de seguridad del producto, el fabricante puede aplicarla; algo contrario atentaría contra el mandato de necesidad.

158 Drexl (1998), p. 253; Schumann (2007), pp. 86 y ss.; Stoll (2003), p. 358. 


\section{Bibliografía CitADA}

Appel, Ivo (1998): Verfassung und Strafe - Zu den verfassungsrechtlichen Grenzen staatlichen Strafens (Berlín, Duncker \& Humblot).

Barrientos Camus, Francisca (2010): "La responsabilidad civil del fabricante bajo el artículo 23 de la Ley de protección de los derechos de los consumidores y su relación con la responsabilidad civil del vendedor", en: Revista Chilena de Derecho Privado (№ 14), pp. 1-49.

(2016): La garantía legal (Santiago de Chile, LegalPublishing Chile).

BARROS BourIE, Enrique (2013): Tratado de responsabilidad extracontractual (Santiago de Chile, Editorial Jurídica de Chile).

BodewiG, Theo (1999): Der Rückruf fehlerhafter Produkte - Eine Untersuchung der Rückrufpflichten und Rückrufansprüche nach dem Recht Deutschlands, der Europäischen Union und der USA (Tubinga, Mohr Siebeck).

BORER, Peter (1986): Produktehaftung: Der Fehlerbegriff nach deutschem, amerikanischem und europäischem Recht (Berna, Haupt).

Bosch, Nikolaus (2002): Organisationsverschulden in Unternehmen (Baden-Baden, Nomos).

BrüGgemeIer, Gert (2006): Haftungsrecht Struktur Prinzipien Schutzbereich - Ein Beitrag zur Europäisierung des Privatrechts (Berlín, Springer).

Bustos Ramírez, Juan, y Hormazábal Malarée, Hernán (1997): Lecciones de derecho penal. Fundamentos del sistema penal, esquema de la teoría del delito y del sujeto responsable y teoría de la determinación de la pena (Madrid, Trotta), Vol. I.

CONTRERAS ChAIMOVICH, Lautaro (2015): "La responsabilidad penal del fabricante por la infracción de sus deberes de vigilancia, advertencia y retirada", en: Política Criminal (Vol. 10, № 19), pp. 266-296.

(2018): Productos defectuosos y derecho penal - El principio de confianza en la responsabilidad penal por el producto (Santiago de Chile, RIL Editores).

Corcor BiDAsolo, Mirentxu (1989): El delito imprudente - Criterios de imputación del resultado (Barcelona, PPU).

(2016): "Protección penal de la salud de los consumidores e imputación de homicidio y lesiones: el caso de la colza", en: Corcoy, Mirentxu, y Gómez, Víctor (Directores), Fraude a consumidores y derecho penal (Montevideo-Buenos Aires, Editorial BdeF), pp. 485-521.

CORRAL TALCIANı, Hernán (2011): Responsabilidad por productos defectuosos - Análisis y propuestas para el derecho civil y de consumo en Chile (Santiago de Chile, LegalPublishing Chile). 
(2013): "artículo 45", en: De la Maza, Íñigo, y Pizarro, Carlos (Directores), La protección de los derechos de los consumidores - Comentarios a la Ley de protección a los derechos de los consumidores (Santiago de Chile, LegalPublishing Chile), pp. 924-928.

CURY URzúA, Enrique (2005): Derecho penal - Parte general, 8 a edición (Santiago de Chile, Ediciones Universidad Católica de Chile).

DeuTsCH, Erwin (1995): Fahrlässigkeit und erforderliche Sorgfalt, $2^{a}$ edición (Colonia, Carl Heymanns).

DOMEIER, Danja (1999): Gesundheitsschutz und Lebensmittelstrafrecht (Fráncfort del Meno, Peter Lang).

DreXL, Josef (1998): Die wirtschaftliche Selbstbestimmung des Verbrauchers Eine Studie zum Privat- und Wirtschaftsrecht unter Berücksichtigung gemeinschaftrechtlicher Bezüge (Tubinga, Mohr Siebeck).

EICHINGER, Harald (1997): Die strafrechtliche Produkthaftung im deutschen im Vergleich zum anglo-amerikanischen Recht (Fráncfort del Meno, Peter Lang).

ENGISCH, Karl (1930): Untersuchungen über Vorsatz und Fahrlässigkeit im Strafrecht (Berlín, Scientia Verlag Aalen).

EtcheberRy Orthustegul, Alfredo (1997): Derecho penal. Parte especial, $3^{\text {a }}$ edición (Santiago de Chile, Editorial Jurídica de Chile), tomo IV.

EXner, Franz (1910): Das Wesen der Fahrlässigkeit (Leipzig/Viena, Deuticke).

FoERSTE, Ulrich (2012a): “§23. Rechtswidrigkeit”, en: Foerste, Ulrich, y Graf Von Westphalen, Friedrich (editores), Produkthaftungshandbuch (Múnich, C.H. Beck), pp. 374-380.

(2012b): "§24. Verkehrspflichten im Bereich der Warenherstellung", en: Foerste, Ulrich, y Graf Von Westphalen, Friedrich (Editores), Produkthaftungshandbuch (Múnich, C.H. Beck), pp. 381-524.

FrEUND, Georg (1991): “Richtiges Entscheiden - am Beispiel derVerhaltensbewertung aus der Perspektive des Betroffenen, insbesondere im Strafrecht Zugleich ein Beitrag zur Relativität objektiver Daten", en: Goltdammer's Archiv für Strafrecht (Vol. 138, № 8), pp. 387-410.

(1992): Erfolgsdelikt und Unterlassen (Colonia, Heymann). (2009): Strafrecht Allgemeiner Teil, $2^{a}$ edición (Heidelberg, Springer). (2015): "Gefährdung als Straftat", en: Freund, Georg, y Rostalski, Frauke (Editores), Strafrechtliche Verantwortlichkeit für Produktgefahren (Fráncfort del Meno, Peter Lang), pp. 141-152.

FrICK, Christina, y KıUTH, Peter (2006): "Produktbeobachtung - Umfang, Reaktion und Kostentragung", en: Produkthaftpflicht International ( $\mathrm{N}^{\circ}$ 6), pp. 206-215. 
FrISCH, Wolfgang (1983): Vorsatz und Risiko Grundfragen des tatbestandsmäßigen Verhaltens und des Vorsatzes - Zugleich ein Beitrag zur Behandlung außertatbestandlicher Möglichkeitsvorstelllungen (Colonia, Carl Heymanns).

(1988): Tatbestandsmäßiges Verhalten und Zurechnung des Erfolgs (Heidelberg, C.F. Müller).

FRISCH, Wolfgang (1992): "Selbstgefährdung im Strafrecht - Grundlinien einer opferorientierten Lehre vom tatbestandsmäßiges Verhalten", en: Neue Zeitschrift für Strafrecht (Vol. 12, Nos. 1 y 2), pp. 1-7, 62-67.

(1993): Verwaltungsakzessorietät und Tatbestandsverständnis im Umweltstrafrecht - Zum Verhältnis von Umweltverwaltungsrecht und Strafrecht und zur strafrechtlichen Relevanz behördlicher Genehmigungen (Heidelberg, C.F. Müller).

(1996 a): "Straftat und Straftatsystem", en: Wolter, Jürgen y Freund, Georg (Editores), Straftat, Strafzumessung und Strafprozeß im gesamten Strafrechtssystem (Heidelberg, C.F. Müller), pp. 135-210.

(1996 b): "Problemas fundamentales de la responsabilidad penal de los órganos de dirección de la empresa - Responsabilidad penal en el ámbito de la responsabilidad de la empresa y de la división del trabajo", en: Mir, Santiago, y Luzón, Diego (Coordinadores), Responsabilidad penal de las empresas y sus órganos y responsabilidad por el producto (Barcelona, Bosch), pp. 99-127.

(2011): "Notstandsregelungen als Ausdruck von Rechtsprinzipien", en: Paeffgen et al. (Editores), Strafrechtswissenschaft als Analyse und Konstruktion - Festschrift für Ingeborg Puppe zum 70. Geburtstag (Berlin, Duncker \& Humblot), pp. 425-450.

(2012): Estudios sobre imputación objetiva (Santiago de Chile, LegalPublishing Chile).

(2014): "Pena, delito y sistema del delito en transformación", en: InDret Revista para el Análisis del Derecho ( $\mathrm{N}^{\circ}$ 6). Disponible en: http://www.indret. $\mathrm{com} / \mathrm{pdf} / 1065 . p d f$ [visitado el 1.10.2017].

GeIss, Joachim, y DolL, Wolfgang (2005): Geräte - und Produktsicherheitsgesetz (GPSG) Kommentar und Vorschriftensammlung (Stuttgart, Kohlhammer).

Grosse Vorholt, André (1997): Behördliche Stellungnahmen in der strafrechtlichen Produkthaftung Zur Konkretisierung von Sorgfaltspflichten bei Risikoentscheidungen (Baden-Baden, Nomos).

HAGER, Günter (1990): “Umwelthaftung und Produkthaftung", en: JuristenZeitung (Vol. 45, No 9), pp. 397-409. 
HAGER, Johannes (2009): "§ 823 F. Die deliktische Produkthaftung", en: Hager, Johannes (Editor), J. von Staudingers Kommentar zum Bürgerlichen Gesetzbuch mit Einführungsgesetz und Nebengesetzen, Buch 2 Recht der Schuldverhältnisse $\S \S 823$ E-I, 824, 825 (Unerlaubte Handlungen 1 - Teilband 2) (Berlín, Sellier - de Gruyter), pp. 270-325.

Hernández Basualto, Héctor (2006): "El problema de la 'causalidad general' en el derecho penal chileno (con ocasión del art. 232 del Anteproyecto de Nuevo Código Penal)", en: Política Criminal (Año 7, № 1). Disponible en: http:// www.politicacriminal.cl/n 01/pdf 01/a 7.pdf [visitado el 1.10.2017].

(2011): "art. 20", en: Couso, Jaime, y Hernández, Héctor (Directores), Código Penal comentado (Santiago de Chile, LegalPublishing), pp. 105-123.

Holst, Katrin (2006): Anforderungen an Warnhinweise auf Produkten Herstellerverantwortung versus Selbstverantwortung des Verbrauchers (Hamburgo, Feldhaus).

Holtermann, Christian (2007): Neue Lösungsansätze zur strafrechtlichen Produkthaftung - Eine Untersuchung unter Heranziehung des Tatbestandes der gemeingefährlichen Vergiftung - §314 Abs. 1 № 2 StGB (Baden-Baden, Nomos).

HöRL, Stephanie(1999): Die unvertretbare Gefahrim deutschen Produkthaftungsrecht

- Ein Neuvorschlag zur Anknüpfung der Haftungsverantwortung des Warenherstellers als Konsequenz neuer US-amerikanischer Entwicklungen und der Allgemeinen Produktsicherheitsrichtlinie der Europäischen Union (Berlín, Duncker \& Humblot).

HOYeR, Andreas (2009): "Erlaubtes Risiko und technologische Entwicklung", en: Zeitschrift für die gesamte Strafrechtswissenschaft (Vol. 121, $\mathrm{N}^{\circ} 4$ ), pp. 860-881.

HufEN, Friedhelm (2017): Staatsrecht I/ Grundrechte, $6^{a}$ edición (Múnich, C. H. Beck).

Í̃̃ıGo, María Elena (2001): La responsabilidad penal del fabricante por defectos de sus productos (Barcelona, J. M. Bosch Editor).

IsLer Soto, Érika (2013): El producto defectuoso en la Ley No 19.496 (Santiago de Chile, Librotecnia).

JAKOBS, Günther (1991): Strafrecht Allgemeiner Teil, 2ª edición (Berlín/New York, De Gruyter).

JeITER, Wolfram, y KLINDT, Thomas (2003): Gerätesicherheitsgesetz Kommentar, $3^{\text {a }}$ edición (Múnich, C. H. Beck). 
JeSCHECK, Hans-Heinrich; WeIGEND, Thomas (1996): Lehrbuch des Strafrechts Allgemeiner Teil, $5^{a}$ edición (Berlin, Duncker \& Humblot).

KAufMANN, Armin (1971): "Tatbestandsmäßigkeit und Verursachung im ConterganVerfahren - Folgerungen für das geltende Recht und für die Gesetzgebung", en: JuristenZeitung (Vol. 26, № 18), pp. 569-576.

KLINDT, Thomas (2007): Geräte - und Produktsicherheitsgesetz Kommentar GPSG (Múnich, C. H. Beck).

KöHLER, Michael (2006): “Die objektive Zurechnung der Gefahr als Voraussetzung der Eingriffsbefugnis im Defensivnotstand", en: Hoyer, Andreas et al. (Editores), Festschrift für Friedrich-Christian Schroeder zum 70 Geburtstag (Heidelberg, C.F. Müller), pp. 257-270.

Kötz, Heinz (1991): "Ist die Produkthaftung eine vom Verschulden unabhängige Haftung?", en: Pfister, Bernhard, y Will, Michael (Editores), Festschrift für Werner Lorenz zum siebzigsten Geburtstag (Tübingen, Mohr Siebeck), pp. 109-121.

KREMER-BAX, Alexandra (1999): Das personale Verhaltensunrecht der FahrlässigkeitstatZur Individualisierung des Bewertungsgegenstands (Fráncfort del Meno, Peter Lang).

KüHL, Kristian (2017): Strafrecht Allgemeiner Teil, 8 a edición (Múnich, Vahlen).

KUHLEN, Lothar (2005): "Die Pflicht zum Rückruf in der strafrechtlichen Produkthaftung", en: Arnold, Jörg (editor), Menschengerechtes Strafrecht Festschrift für Albin Eser zum 70. Geburtstag (Múnich, C. H. Beck), pp. 359-372. (2015): "1. Kapitel Strafrechtliche Produkthaftung", en: Achenbach, Hans et al. (Editores), Handbuch Wirtschaftsstrafrecht, $4^{a}$ edición (Heidelberg, C.F. Müller), pp. 107-147.

LORENZ, Dieter (1965): Der Maßstab des einsichtigen Menschen (Múnich, Ludwig Maximilians Universität).

Mañalich RafFo, Juan Pablo (2010): “Norma e imputación como categorías del hecho punible", en: Revista de Estudios de la Justicia (№ 12), pp. 169-190.

MAYER, Michael (2008): Strafrechtliche Produktverantwortung bei Arzneimittelschäden - Ein Beitrag zur Abgrenzung der Verantwortungsbereiche im Arzneiwesen aus strafrechtlicher Sicht (Berlín, Springer).

MEYER, Justus (1992): Instruktionshaftung - Eine Analyse aus der Sicht der Recht-, Wirtschafts- und Verhaltenswissenschaften (Bielefeld, Gieseking).

MıCHALSkı, Lutz (1998): "Produktbeobachtung und Rückrufpflicht des Produzenten", en: Betriebs-Berater ( $\left.N^{\circ} 19\right)$, pp. 961-966. 
MölleRS, Thomas M. J. (1996): Rechtsgüterschutz im Umwelt - und Haftungsrecht Präventive Verkehrspflichten und Beweiserleichterungen in Risikolagen (Tubinga, Mohr Siebeck).

Murmann, Uwe (2017): Grundkurs Strafrecht, 4a edición (Múnich, C.H. Beck).

Paredes Castañón, José Manuel (2000): "De nuevo sobre el 'caso de la colza' - Una réplica", en: Revista de Derecho Penal y Criminología (№ 5), pp. 87-126.

(2011): "23. Caso del aceite de colza", en: Sánchez-Ostiz, Pablo (Coordinador), Casos que hicieron doctrina en derecho penal (Madrid, La Ley), pp. 425-439.

PupPE, Ingeborg (2017): "Vorbemerkungen zu §§ 13 ff", en: Kindhäuser, Urs et al. (Editores), Strafgesetzbuch Band 1, 5a edición (Baden-Baden, Nomos), pp. 513-650.

RetTenBeCk, Stephan (1994): Die Rückrufpflicht in der Produkthaftung - Zugleich ein Beitrag zur EG-Richtlinie über die allgemeine Produktsicherheit vom 29. Juni 1992 (Baden-Baden, Nomos).

Reus, Katharina (2010): Das Recht in der Risikogesellschaft - Der Beitrag des Strafrechts zum Schutz vor modernen Produktgefahren (Berlín, Duncker \& Humblot).

Rodríguez Montañés, Teresa (1996): "Problemas de responsabilidad penal por comercialización de productos adulterados: algunas observaciones acerca del 'caso de la Colza' (Primera Parte)', en: Mir Puig, Santiago, y Luzón Peña, Diego-Manuel (Coordinadores), Responsabilidad penal de las empresas y sus órganos y responsabilidad por el producto (Barcelona, J. M. Bosch), pp. 263-287.

Rojas AguiRre, Luis Emilio (2013): "Accesoriedad del derecho penal", en: Van Weezel, Álex (Editor), Humanizar y renovar el derecho penal - Estudios en memoria de Enrique Cury (Santiago de Chile, LegalPublishing Chile), pp. 93-107.

Salvador Coderch, Pablo, y Ramos González, Sonia (2008): "Capítulo IV Defectos de producto", en: Salvador, Pablo, y Gómez, Fernando (Directores), Tratado de responsabilidad civil del fabricante (Cizur Menor, Thomson Civitas), pp. 135-219.

Schmidt-Salzer, Joachim (1982): Entscheidungssammlung Produkthaftung, Bd. IV: Mit einer Einführung und Urteilsanmerkungen, Strafrechtliche Entscheidungen, Gesamtregister Bd. I-IV (Múnich, Schweitzer).

(1990): Produkthaftung, Bd. III/1: Deliktsrecht 1. Teil, $2^{\text {a }}$ edición (Heidelberg, Recht und Wirtschaft). 
(1988): Joachim, Produkthaftung - Bd. I Strafrecht, $2^{\text {a }}$ edición (Heidelberg, Recht und Wirtschaft).

Schumann, Florian (2007): Bauelemente des europäischen Produktsicherheitsrechts (Baden-Baden, Nomos).

Sieckmann, Jan-Reinard (1995): "Abwägung von Rechten", en: Archiv für Rechtsund Sozialphilosophie (Vol. 81, № 3), pp. 164-184.

SternBERG-Lieben, Detlev, y SCHuster, Frank (2014): "StGB § 15 Vorsätzliches und fahrlässiges Handeln", en: AA. VV., Strafgesetzbuch Kommentar, $29^{a}$ edición (Múnich, C. H. Beck), pp. 246-340.

Stoll, Peter-Tobias (2003): Sicherheit als Aufgabe von Staat und Gesellschaft Verfassungsordnung, Umwelt- und Technikrecht im Umgang mit Unsicherheit und Risiko (Tubinga, Mohr Siebeck).

Tiмm, Frauke (2012): Gesinnung und Straftat (Berlín, Duncker \& Humblot).

Von Bar, Christian (1998): "Die Grenzen der Haftung des Produzenten", en: Lieb, Manfred (Editor), Produktverantwortung und Risikoakzeptanz - Kriterien der Risikoverteilung - Wissenschaftliches Symposion der Bayer-Stiftung für deutsches und internationales Arbeits- und Wirtschaftsrecht am 28. und 29. november 1996 in Leverkusen (Múnich, C. H. Beck), pp. 29-47.

WAGNER, Gerhard (2017): "§ 823 Schadenersatzpflicht". Disponible en: http:// www.beck-online.beck.de/Home [visitado el 1.10.2017].

WAGNeR, Gerhard, y WiTTE, Lorenz (2005): "Anmerkung zu Cour de cassation, 2e civ., Urt. v. 20.11.2003", en: Zeitschrift für europäisches Privatrecht (Año $\left.13, N^{\circ} 4\right)$, pp. 895-918.

WeIsS, Holger (2008): Die rechtliche Gewährleistung der Produktsicherheit (Baden-Baden, Nomos).

Wessels, Johannes et al. (2017): Strafrecht Allgemeiner Teil Die Straftat und ihr Aufbau, 47 $7^{\mathrm{a}}$ edición (Heidelberg: Müller).

WILRICH, Thomas (2004): Geräte- und Produktsicherheitsgesetz (GPSG) Gesetz über technische Arbeitsmittel und Verbraucherprodukte (Berlín, Springer).

ZACZYK, Rainer (1989): Das Unrecht der versuchten Tat (Berlin, Duncker \& Humblot).

\section{NORMATIVA CHILENA CITADA}

Ley N N 19.946, sobre protección de los derechos de los consumidores. Diario Oficial, 7 de marzo de 1997.

Ley N N 19.039, de Propiedad Industrial. Diario Oficial, 25 de enero de 1991. 
Ley $N^{\circ} 17.798$, sobre control de armas. Diario Oficial, 21 de octubre de 1972. Código Sanitario. Diario Oficial, 31 de enero de 1968.

Código Penal. Diario Oficial, 12 de noviembre de 1874.

Reglamento del sistema nacional de control de los productos farmacéuticos de uso humano. Diario Oficial, 25 de junio de 2011.

Reglamento sobre seguridad de los juguetes. Diario Oficial, 17 de junio de 2005. Reglamento sanitario de los alimentos. Diario Oficial, 13 de mayo de 1997. Resolución Exenta № 636 del Ministerio de Salud, que establece dosis máximas de irradiación de alimentos. Diario Oficial, 6 de septiembre de 2014.

\section{Normativa EXTRANJERA CITADA}

Produktsicherheitsgesetz - ProdSG. Bundesgesetzblatt, 11 de noviembre de 2011. Real Decreto sobre seguridad general de los productos. Boletín Oficial del Estado, 10 de enero de 2004.

\section{JURISPRUDENCIA NACIONAL Y EXTRANJERA CITADA}

Acusado Roberto Oetiker y otros (2012): Tribunal de Juicio Oral en lo Penal de San Bernardo 24 agosto 2012 (procedimiento ordinario) en: Base de datos de la Corporación Administrativa del Poder Judicial.

Partes sin indicación de iniciales (2009): Tribunal Supremo Federal alemán 16 junio 2009 (recurso de casación) en: Neue Juristische Wochenschrift (NJW) 2009, pp. 2952-2956.

Recurrente P. y otros (2005): Tribunal Constitucional Federal alemán 12 abril 2005 (recurso de amparo constitucional) en: Entscheidungen des Bundesverfassungsgerichts (BVerfGE) 113, pp. 29-63.

Partes sin indicación de iniciales (2005): Tribunal del Land Essen 12 mayo 2005 (procedimiento ordinario) en: Neue Juristische Wochenschrift (NJW) 2005, pp. 2713-2716.

Recurrente Gobierno del Estado Federal de Baden-Württemberg y otros (2005): Tribunal Constitucional Federal alemán 18 julio 2005 (control de constitucionalidad de la ley) en: Entscheidungen des Bundesverfassungsgerichts (BVerfGE) 113, pp. 167-273.

Partes sin indicación de iniciales (2002): Tribunal del Land Mönchengladbach 24 abril 2002 (procedimiento ordinario) en: Neue Juristische Wochenschrift Rechtsprechungs-Report Zivilrecht (NJW-RR) 2002, pp. 896-899. 
Luis A. M. y Josefina V. M. con Interdulces S.A. y Ana María G. J. (2002): Tribunal Supremo español 10 junio 2002 (recurso de casación) en: Repertorio de Jurisprudencia Aranzadi 2002, pp. 11028-11030.

Partes sin indicación de iniciales (2002): Tribunal Superior del Land Düsseldorf 20 diciembre 2002 (recurso de apelación) en: Versicherungsrecht (VersR) 2003, pp. 912-917.

Partes sin indicación de iniciales (2001): Tribunal Superior del Land Karlsruhe 29 marzo 2001 (recurso de apelación) en: Neue Juristische Wochenschrift Rechtsprechungs-Report Zivilrecht (NJW-RR) 2001, p. 1174.

Recurrente Tribunal Laboral Heilbronn (2001): Tribunal Constitucional Federal alemán 3 abril 2001 (control de constitucionalidad de la ley) en: Entscheidungen des Bundesverfassungsgerichts (BVerfGE) 103, pp. 293-309.

Partes sin indicación de iniciales (1999): Tribunal Supremo Federal alemán 18 mayo 1999 (recurso de casación) en: Neue Juristische Wochenschrift (NJW) 1999, pp. 2815-2817.

Acusado G. (1999): Tribunal Superior del Land Karlsruhe 16 diciembre 1999 (recurso de casación) en: NStZ-Rechtsprechungsreport Strafrecht (NStZ-RR) 2000, pp. 141-143.

Recurrente Tribunal del Land Kirchhain (1997): Tribunal Constitucional Federal alemán 10 abril 1997 (control de constitucionalidad de la ley) en: Entscheidungen des Bundesverfassungsgerichts (BVerfGE) 96, pp. 10-27.

Recurrente sin indicación de iniciales (1996): Tribunal Constitucional Federal alemán 16 octubre 1996 (recurso de amparo constitucional) en: Neue Juristische Wochenschrift (NJW) 1997, pp. 249-250.

Partes sin indicación de iniciales (1995): Tribunal Supremo Federal alemán 31 enero 1995 (recurso de casación) en: Neue Juristische Wochenschrift (NJW) 1995, pp. 1286-1289.

Acusado Juan Miguel Bengoechea y otros (1992): Tribunal Supremo español 23 abril 1992 (recurso de casación) en: Repertorio de Jurisprudencia Aranzadi 1992, pp. 8827-8933.

Partes sin indicación de iniciales (1991): Tribunal Supremo Federal alemán 12 noviembre 1991 (recurso de casación) en: Entscheidungen des Bundesgerichtshofes in Zivilsachen (BGHZ) 116, pp. 60-77.

Acusado S. y otros (1990): Tribunal Supremo Federal alemán 6 julio 1990 (recurso de casación) en: Entscheidungen des Bundesgerichtshofes in Strafsachen (BGHSt) 37, pp. 106-135. 
Partes sin indicación de iniciales (1989): Tribunal Supremo Federal alemán 24 enero 1989 (recurso de casación) en: Entscheidungen des Bundesgerichtshofes in Zivilsachen (BGHZ) 106, pp. 273-284.

Partes sin indicación de iniciales (1989): Tribunal Supremo Federal alemán 17 octubre 1989 (recurso de casación) en: Neue Juristische Wochenschrift (NJW) 1990, pp. 906-908.

Acusado sin indicación de iniciales (1987): Tribunal Supremo español 22 abril 1987 (recurso de casación) en: Repertorio de Jurisprudencia Aranzadi 1987, pp. 2434-2435.

Partes sin indicación de iniciales (1986): Tribunal Supremo Federal alemán 4 febrero 1986 (recurso de casación) en: Neue Juristische Wochenschrift (NJW) 1986, pp. 1863-1865.

Partes sin indicación de iniciales (1986): Tribunal del Land Frankfurt/Main 24 marzo 1986 (recurso de apelación) en: Neue Juristische Wochenschrift Rechtsprechungs-Report Zivilrecht (NJW-RR) 1986, pp. 658-659.

Partes sin indicación de iniciales (1986): Tribunal Supremo Federal alemán 7 octubre 1986 (recurso de casación) en: Neue Juristische Wochenschrift (NJW) 1987, pp. 372-374.

Partes sin indicación de iniciales (1986): Tribunal Supremo Federal alemán 9 diciembre 1986 (recurso de casación) en: Neue Juristische Wochenschrift (NJW) 1987, pp. 1009-1012.

Recurrente M. (1984): Tribunal Constitucional Federal alemán 20 junio 1984 (recurso de amparo constitucional) en: Entscheidungen des Bundesverfassungsgerichts (BVerfGE) 67, pp. 157-185.

Recurrente G. y otros (1983): Tribunal Constitucional Federal alemán 27 enero 1983 (recurso de amparo constitucional) en: Entscheidungen des Bundesverfassungsgerichts (BVerfGE) 63, pp. 88-119.

Partes sin indicación de iniciales (1981): Tribunal Supremo Federal alemán 17 marzo 1981 (recurso de casación) en: Entscheidungen des Bundesgerichtshofes in Zivilsachen (BGHZ) 80, pp. 186-199.

Partes sin indicación de iniciales (1981): Tribunal Supremo Federal alemán 7 julio 1981 (recurso de casación) en: Neue Juristische Wochenschrift (NJW) 1981, pp. 2514-2516.

Recurrente O. (1980): Tribunal Constitucional Federal alemán 16 enero 1980 (recurso de amparo constitucional) en: Entscheidungen des Bundesverfassungsgerichts (BVerfGE) 53, pp. 135-147. 
Acusados sin indicación de iniciales (1978): Tribunal del Land Múnich II 21 abril 1978 (procedimiento ordinario) en: SCHMIDT-SALZER, Joachim (1982): Entscheidungssammlung Produkthaftung, Bd. IV: Mit einer Einführung und Urteilsanmerkungen, Strafrechtliche Entscheidungen, Gesamtregister Bd. I-IV (Múnich, Schweitzer), pp. 296-337.

Recurrente Klaus Jünschke y otros (1978): Tribunal Constitucional Federal alemán 1 agosto 1978 (recurso de amparo constitucional) en: Entscheidungen des Bundesverfassungsgerichts (BVerfGE) 49, pp. 24-70.

Partes sin indicación de iniciales (1975): Tribunal Supremo Federal alemán 3 junio 1975 (recurso de casación) en: Neue Juristische Wochenschrift (NJW) 1975, pp. 1827-1829.

Recurrente Z. y otros (1974): Tribunal Constitucional Federal alemán 18 diciembre 1974 (recurso de amparo constitucional) en: Entscheidungen des Bundesverfassungsgerichts (BVerfGE) 38, pp. 281-312.

Parte sin indicación de iniciales con empresa R. (1972): Tribunal Supremo Federal alemán 11 julio 1972 (recurso de casación) en: Neue Juristische Wochenschrift (NJW) 1972, pp. 2217-2222.

Acusados sin indicación de iniciales (1970): Tribunal del Land Aquisgrán 18 diciembre 1970 (procedimiento ordinario) en: JuristenZeitung (JZ) 1971, pp. 507-521.

Partes sin indicación de iniciales (1968): Tribunal Supremo Federal alemán 26 noviembre 1968 (recurso de casación) en: Entscheidungen des Bundesgerichtshofes in Zivilsachen (BGHZ) 51, pp. 91-108.

Acusado sin indicación de iniciales (1959): Tribunal Supremo Federal alemán 17 febrero 1959 (recurso de casación) en: SCHMidT-SAlzer, Joachim (1982): Entscheidungssammlung Produkthaftung, Bd. IV: Mit einer Einführung und Urteilsanmerkungen, Strafrechtliche Entscheidungen, Gesamtregister Bd. I-IV (Múnich, Schweitzer), pp. 170-175.

Partes sin indicación de iniciales (1959): Tribunal Supremo Federal alemán 14 abril 1959 (recurso de casación) en: Versicherungsrecht (VersR) 1959, pp. 523-525.

Acusado sin indicación de iniciales (1958): Tribunal Supremo Federal alemán 10 julio 1958 (recurso de casación) en: Entscheidungen des Bundesgerichtshofes in Strafsachen (BGHSt) 12, pp. 75-81.

Acusado sin indicación de iniciales (1953): Tribunal Supremo Federal alemán 23 abril 1953 (recurso de casación) en: Entscheidungen des Bundesgerichtshofes in Strafsachen (BGHSt) 4, pp. 182-187. 